\title{
Quantification of the main digestive processes in ruminants: the equations involved in the renewed energy and protein feed evaluation systems
}

\author{
D. Sauvant ${ }^{1,2 \dagger}$ and P. Nozière ${ }^{3,4}$ \\ ${ }^{1}$ INRA, UMR 791 MoSAR, 16 rue Claude Bernard, 75231 Cedex 05, Paris, France; ${ }^{2}$ AgroParisTech, UMR 791 MoSAR, 16 rue Claude Bernard, 75231 Cedex 05, Paris, France; \\ ${ }^{3}$ INRA, UMR 1213 Herbivores, Theix, 63122 Saint Genès Champanelle, France; ${ }^{4}$ VetAgroSup, UMR 1213 Herbivores, Theix, 63122 Saint Genès Champanelle, France
}

(Received 19 December 2014; Accepted 31 October 2015; First published online 23 December 2015)

\begin{abstract}
The evolution of feeding systems for ruminants towards evaluation of diets in terms of multiple responses requires the updating of the calculation of nutrient supply to the animals to make it more accurate on aggregated units (feed unit, or UF, for energy and protein digestible in the intestine, or PDI, for metabolizable protein) and to allow prediction of absorbed nutrients. The present update of the French system is based on the building and interpretation through meta-analysis of large databases on digestion and nutrition of ruminants. Equations involved in the calculation of UF and PDI have been updated, allowing: (1) prediction of the out flow rate of particles and liquid depending on the level of intake and the proportion of concentrate, and the use of this in the calculation of ruminal digestion of protein and starch from in situ data; (2) the system to take into account the effects of the main factors of digestive interactions (level of intake, proportion of concentrate, rumen protein balance) on organic matter digestibility, energy losses in methane and in urine; (3) more accurate calculation of the energy available in the rumen and the efficiency of its use for the microbial protein synthesis. In this renewed model UF and PDI values of feedstuffs vary depending on diet composition, and intake level. Consequently, standard feed table values can be considered as being only indicative. It is thus possible to predict the nutrient supply on a wider range of diets more accurately and in particular to better integrate energy $x$ protein interactions occurring in the gut.
\end{abstract}

Keywords: feed unit system, ruminant, digestion, nitrogen, meta-analysis

\section{Implications}

The feed unit systems have been a major factor of progress in livestock sector for calculating the most appropriate diets. For more than a century and a half, these systems have been periodically updated to reflect advances in scientific knowledge and new challenges of the sector. In recent years the production of knowledge on the nutrition of ruminants has experienced strong growth, thanks to advances in research in emerging countries. Meanwhile, new economic, environmental and societal challenges require the adoption of a multi-criteria feeding system. We present a quantitative integration of the main digestive mechanisms involved in the evolution of the INRA feed unit system for ruminants. One of the consequences is that tabulated feed values are now only indicative.

\section{Introduction}

Feed unit systems (FUS) for animals have existed for decades. Fairly accurate FUS were already proposed in the second part of

\footnotetext{
${ }^{\dagger}$ E-mail: daniel.sauvant@agroparistech.fr
}

the 19th century, consequent on progress in the analysis of feedstuffs and in digestibility measurements on animals (Henneberg and Stohmann, 1860). The construction of these FUS was based on the integration of basic knowledge on food digestion and metabolic utilization of absorbed nutrients into units that expressed both the requirements of the animals and the nutritive values of feed. These systems have been additive to allow easy calculation of rations, and were designed such that their implementation was not expensive. Several FUS have been developed around the world, particularly in European countries and in the United States, some of them have been regularly updated and thus they are key factor of progress in animal nutrition.

For many years the progress in the FUS was obtained through more accurate predictions of the animal requirements and feed values. However, in recent decades, new concerns and challenges for animal production appeared and became more and more important. The need for a more efficient utilization of feed and animal resources, a reduction of waste from the animal which could alter the environment $(\mathrm{N}, \mathrm{P}, \mathrm{CH} 4 . .$.$) , a better control of composition of products to fit$ 
the demand of consumers, the necessity to improve the health and welfare of animals, etc. It has become increasingly clear that these multiple concerns must be taken into consideration in animal nutrition (Sauvant, 1992 and 1999). As a consequence, FUS should evolve towards a prediction of (the above mentioned) multiple responses of animals to changes in diets and feeding practices. Therefore it has become necessary to understand the digestive and metabolic processes at the level of key nutrients, and hence be able to predict their impacts on animal responses.

To-date, no feeding system has been entirely targeted at predicting animal responses to diets. However, the issue of predicting elements of animal responses has already appeared with, for instance, the prediction of metabolizable protein (MP) efficiency to milk (Vérité et al., 1987; Thomas, 2004; Van Duinkerken et al., 2011; Volden, 2011) and the prediction of production responses to lysine and methionine contents of MP (Verité et al., 2001).

To achieve this goal, a necessary first step concerns the extension of the digestive part of the current INRA FUS. This currently only poorly integrates protein - energy interactions and phenomena of digestive interactions. Consequently, the current INRA FUS does not accurately apply to extreme diets, such as low nitrogen or high cell-wall diets that are encountered in temperate countries, or to very high energy density diets ingested at high feeding levels (FL). The objective of this work, part of the INRA-Systali project, was to renew the calculation of the energy and protein feed values, taking into account more accurately the main digestive phenomena (digestive interactions, passage rates, microbial synthesis and protein $\times$ energy interactions), and thereby improve prediction of absorbed nutrients.

\section{Rationale and approach}

\section{Global issues}

We used a meta-analysis approach to derive improved regressions describing the main mechanisms of digestion, as affected by the variations in diet composition related to current feeding practices. This included re-evaluation of the major digestive mechanisms already included in existing FUS, as well as other mechanisms, which might present a potential interest to be integrated in order to improve the accuracy and the practical implementation of these systems.

\section{Databases}

Two main databases gathering data of means of experimental groups from published literature and from INRA laboratories were used:

- A database on quantitative digestion in cattle (BoviDig, UMR MoSAR, INRA, Paris) containing: 496 publications (pub), 811 experiments (exp), 2136 treatments (trt). The minimum information requirements for a study to be included in the data set were: CP contents ( $/ \mathrm{kg} \mathrm{DM}$ ), dry-matter intake (DMI, $\mathrm{kg} /$ day) as concentrate and forage, and body weight (BW, $\mathrm{kg}$ ). Further, the publication must have reported data on either digestibility, or nitrogen balance, or chewing activity. Lactating cows represented $67.0 \%$ of the treatments. The forage was either alfalfa $(46.0 \%$ of $\mathrm{trt})$, or graminacae excluding maize (35.6\% of trt) or maize $(37.6 \%$ of trt). A sub-data set corresponding to the experiments on the quantitative or qualitative influence of nitrogen (BoviDig_PDI, 161 exp, $423 \mathrm{trt}$, year of publication $1993 \pm 7.3$ ), was identified. To minimize variation due to local differences in calculation of digestibility and degradability values, all diets in this subset were characterized according to the INRA (2007) method. Another sub-data set corresponding to the experiments on the quantitative or qualitative influence of starch (BoviDig Starch, 116 exp, 283 trt, year of publication $1992 \pm 7.0$ ), was identified and likewise characterized for the dietary starch content and in situ degradability, according to Offner et al. (2003).

- A database of calorimetric measurements on various cattle and small ruminants (Rumener, UMR MoSAR, INRA, Paris): 188 pub, 273 exp, 1193 trt.

Given that most equations were developed from bovine data, external evaluations were performed to check the consistency of equations for small ruminant using the following databases:

- A database on quantitative digestion in sheep (OviDig, UMR Herbivores, INRA, Theix): 110 pub, 170 exp, 510 trt. In this database, 280 trt were characterized according to INRA (2007) recommendations.

- A database on digestibility and nitrogen balance in goats (Caprinut, UMR MoSAR, INRA, Paris): 145 exp, 421 trt, all characterized according to INRA (2007) recommendations.

All abbreviations are reported in the Supplementary material S1.

\section{Data encoding}

In these databases, all experiments and treatments within experiments were coded. The major experimental factors were identified and the treatments were encoded accordingly, in order to properly assess the specific effects of each of these factors. Thus a specific code and column was created for each particular experimental objective (Sauvant et al., 2008). Operational encodings were also applied to identify experiments having large variations in protein or energy content despite the fact that this was not the main objective for the study. This makes it easy possible the selection of experiments with similar objective and ensures when possible a maximum of consistency between objectives and covariables for the statistical treatment (see below).

\section{Statistical analysis}

The meta-analysis method proposed by Sauvant et al. (2008) was used. This combined a careful graphical examination of the meta-design with the use of GLM partition variance into withinand inter-experiment variance. Within-experiment relationships were considered to better reflect quantitative relationships between digestive events in response to feeding practices. 
For each within-experiment relationship, the number of trt $(n)$ and of $\exp (n \exp )$ taken into account was reported as well as the residual standard deviation (RSD). No weighing of either treatments or experiments was applied as equations and conclusions were not modified in this case. Within-experiment relationships were estimated including the experiment as a fixed effect, assuming no hypothesis on their statistical distribution and allowing subsequent exploration of inter-experiment heterogeneity (Sauvant et al., 2008; Loncke et al., 2009; Guyader et al., 2014). Normality of residuals was tested (Anderson-Darling test), and treatments with normalized residuals $<-3$ or $>+3$ were identified and discarded as statistical outliers, as well as, less frequently, treatments that had a high leverage effect based on Hi calculation and Cook distance. By this way $<5 \%$ of the treatments have been discarded.

\section{Consistency between equations}

Among many equations generated, only the most relevant in terms of statistical quality and biological significance were retained. Given that they were obtained from several distinct data sets, they were introduced within an aggregated and simple mechanistic model of digestion which is not presented here (Sauvant and Nozière, 2012), to check the consistency among them. The equations presented in this paper mainly concern the calculation of energy (UFL and UFV) and protein (PDI) feed values, that is prediction of fractional passage rates in the rumen, digestion of protein and starch, digestive interactions, fermentable organic matter in the rumen, microbial protein synthesis, digestion in the intestines and the loss of energy in $\mathrm{CH} 4$ and urine. A diagrammatic presentation of the articulations between these equations is presented at the end of the paper. For each part, the new proposal is compared to the previous versions of the INRA systems, and to recent proposals of other countries.

\section{Derived equations and discussion}

Fractional passage rates in the rumen

Prediction. In ruminants, fractional passage rates in the rumen determine the availability of substrates for degradation by microorganisms, as well as the efficiency of microbial growth. Several studies conducted using markers of the liquid and particulate fractions have shown that the fractional passage rate of digesta largely depends on intake level. It also differs between liquid and particulate phases, forage $v$. concentrate particles, size of particles (Owens and Goetsch, 1986), and according to the nature of components (protein, starch, cell wall).

In the initial version of the PDI system (INRA, 1978 and 1988 and 2007), the fractional passage rate (kpt) was fixed at $6 \% / \mathrm{h}$ for potentially degradable particles, and was not considered for soluble fractions that were assumed to be immediately degraded. In the DVE/OEB system, fractional passage rate was fixed at $4.5 \% / \mathrm{h}$ for forages ( $\mathrm{kft}$ ) and $6 \% / \mathrm{h}$ for concentrates (kct; Tamminga et al., 1994). Rather similar equations based on $\mathrm{DMI}, \%$ forage and NDF fraction were proposed by NRC with a difference between wet and dry forages (NRC, 2001). In the
NorFor system (Volden, 2011), fractional passage rates were dissociated between forages and concentrates and dependent on the level of $\mathrm{DMI} / \mathrm{BW}^{0.75}$ and the proportion of forage in the diet; they used, as did the Cornell Net Carbohydrate and Protein System (CNCPS) (Sniffen et al., 1992), and Feed into Milk (FiM) systems (Thomas, 2004), the equations initially proposed in 1990 by Sauvant and Archimède, cited by Sauvant et al. (1995). In these equations the prediction of kct was indexed on the $\mathrm{kft}$ values. In contrast, in the proposals of NRC (2001) and Seo et al. (2006), both kft and kct calculations were based on DMI/BW and on the proportion of forage in the diet. Moreover, in NorFor (Volden, 2011) there is a specific equation to predict the low outflow rates of the non-digestible NDF fractions of forages and concentrates. In the current DVE/ $\mathrm{OEB}_{2010}$ system (Van Duinkerken et al., 2011), separate fractional passage rates were proposed for $\mathrm{CP}$, starch, NDF and remainder non starch polysaccharides, in addition to the distinction between liquids, concentrate and forage particles. Contrasting with other proposals, the Dutch one did not include any influence of DMI and proportion of forage, they only used predictions based on feed density. We did not retain the feed density because it is poorly documented in the literature.

Using the BoviDig database, the FL (varying from 1 to $4.5 \mathrm{~g}$ $\mathrm{DM} / 100 \mathrm{~g} \mathrm{BW})$ and the proportion of concentrate $(0<\mathrm{PCO}<1)$ were found to be the main predictive factors for fractional passage rates $(\% / \mathrm{h})$ of forage particles $(\mathrm{kft}=3.38 \pm 1.29$, $\min =1.18, \quad \max =7.1 \% / \mathrm{h})$, concentrate particles $(\mathrm{kct}=$ $5.97 \pm 1.88, \quad \min =2.05, \quad \max =11.2 \% / \mathrm{h})$, and liquids (klt $=10.23 \pm 3.54, \min =3.00, \max =22.30 \% / \mathrm{h}$ ), actually measured using markers. The predictive equations are:

$$
\begin{aligned}
& \mathrm{kft}=2.02+0.88 \mathrm{FL}-3.13 \mathrm{PCO}^{2} \\
& \quad(n=236, n \exp =95, \mathrm{RSD}=0.41 \% / \mathrm{h}) \\
& \mathrm{kct}=2.53+1.22 \mathrm{FL}-2.61 \mathrm{PCO}{ }^{2} \\
& \quad(n=115, n \exp =46, \mathrm{RSD}=0.51 \% / \mathrm{h}) \\
& \mathrm{klt}=5.35+2.18 \mathrm{FL}-3.71 \mathrm{PCO}{ }^{2} \\
& \quad(n=582, n \exp =236, \mathrm{RSD}=0.87 \% / \mathrm{h})
\end{aligned}
$$

The mean fractional passage rate of particles (kpt) within a given diet can be calculated from kft, kct and PCO.

$$
\mathrm{kpt}=\mathrm{kft}(1-\mathrm{PCO})+\mathrm{kct} P C O
$$

These equations, illustrated in Figure 1 in the case of a mean value of $\mathrm{PCO}$, show that within a given diet fractional passage rate is lower for forage particles that require more mastication, than for concentrate particles. They also reflect the finding that the motility of the rumen decreases when PCO increases, as already observed by Owens and Goetsch (1986). Equations (1) and (2) illustrate that the value of $6 \% / \mathrm{h}$ fixed in the $\mathrm{PDI}_{1988}$ system is never reached by forage particles, and only reached by concentrate particles when FL exceeds $\sim 3.5 \mathrm{~g} / 100 \mathrm{~g} \mathrm{BW}$. This means that compared to the $\mathrm{PDI}_{1988}$ system, the residence time of feed fractions (i.e. nitrogen) in the rumen is supposed to be 

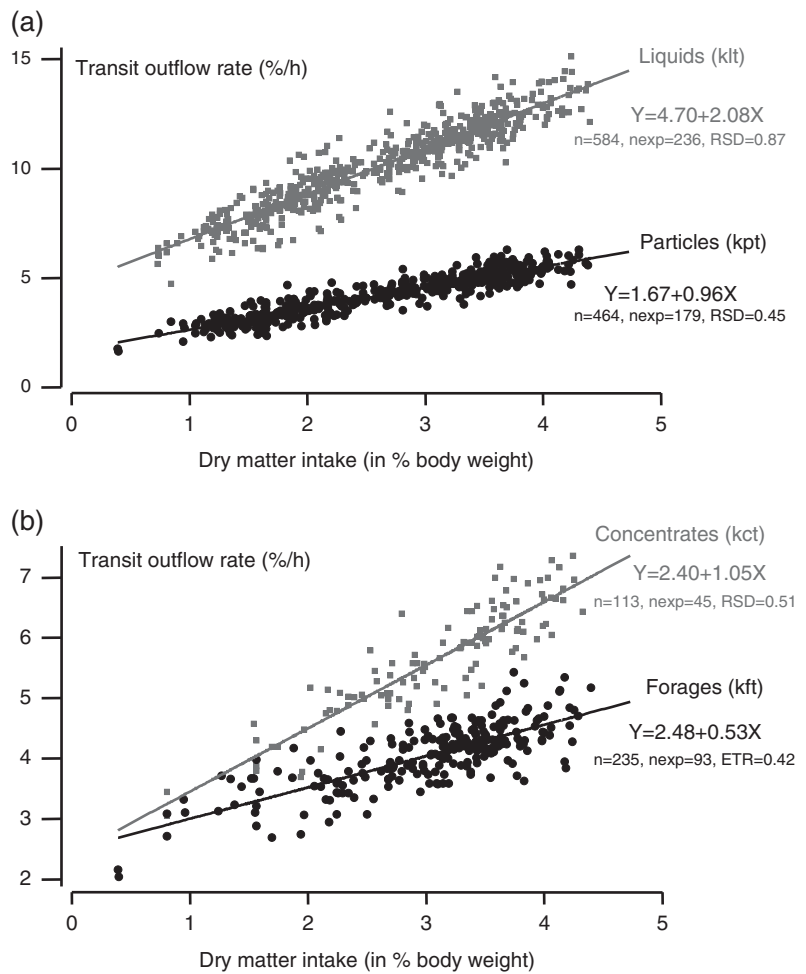

Figure 1 Intra-experiment relationship between dry matter intake in cattle and (a) transit outflow rates of liquids and particles; (b) outflow rates of forages and concentrates.

longer, resulting in a lower fraction escaping microbial degradation. We have checked that the values of fractional passage rates calculated by equations (1) to (3) are close $(<1 \% / \mathrm{h}$ of difference) to the values calculated by the similar equations proposed in Sauvant et al. (1995), NRC (2001), NorFor (Volden, 2011), FiM (Thomas, 2004) and Seo et al. (2006).

Implications on revised feed tables. To account for the effect of FL and PCO on fractional passage rate and therefore on digestion and nutritive values, each feedstuff is classified either as a forage, or as a concentrate, as already described in INRA (2007) except that dehydrated forages are considered as forages. Moreover, each feedstuff is characterized in the revised feed tables by a reference $\mathrm{FL}$ (FLref, in g DMI/100 g BW). For forages, the FLref corresponds to the ad libitum intake of DM of a given forage by standard castrated sheep, which has been used for decades at INRA for measurement of forage digestibility and energy value (Demarquilly and Weiss, 1970; Andrieu et al., 1988; Baumont et al., 2007). This value ranges from 1.1 (low-quality hays) to 3.4 (early fresh grass); the only exception is corn silage, for which the calculations are performed with a constant FLref of 1.44 as suggested by Andrieu et al. (1988). For concentrates and co-products, it is considered in the tables that FLref $=2$, that is the average value for the most commonly used forages.

\section{Digestion of protein and starch in the rumen}

The in situ approach. For proteins and starch, the prediction of the digestion in the rumen is often based on the integration of in situ degradation kinetics obtained by the method of nylon bags incubated in the rumen and removed after various incubation times (Michalet-Doreau et al., 1987). In contrast, this approach has not been retained for NDF because the in situ degradation of NDF is highly sensitive to the ruminal environment (Nozière et al., 1996; Archimède et al., 1997), and because data are less numerous than for protein and starch.

The effective degradability (ED in $\mathrm{g} / 100 \mathrm{~g}$ ) of proteins and starch results from the combination of the fractional passage rate, and the fractional degradation rate of their different fractions:

$$
E D=a[100 /(100+k l t)]+b[k d /(k d+k p t)]
$$

In this equation, a $(\mathrm{g} / 100 \mathrm{~g})$ is the washable and rapidly degradable fraction; it is assumed to be degraded at a fractional rate of $100 \% / \mathrm{h}$, and to outflow the rumen with the liquid phase at the fractional rate klt (equation (3)). This fractional degradation rate is not easy to know precisely; therefore the current FUS adopted a common high value (either 100 , or 150 or 200 ) for all feeds. The fraction $b$ $(\mathrm{g} / 100 \mathrm{~g})$ is the potentially degradable one; it is assumed to be degraded at a fractional rate $\mathrm{kd}(\% / \mathrm{h})$, and to outflow the rumen with the particulate phase at the fractional rate $\mathrm{kft}$ for forage (equation (1)) or kct for concentrate (equation (2)).

In order to estimate $a, b$ and $k d$, degradation $(D(t)$, in $\mathrm{g} / 100 \mathrm{~g})$ as a function of time $(t$, in $\mathrm{h})$, is fitted using a first-order exponential model (Ørskov and McDonald, 1979):

$$
\mathrm{D}(t)=\mathrm{a}+\mathrm{b} \times\left(1-\exp ^{-\mathrm{kd} \times t}\right)
$$

when $a, b$ and kd are not known and when the effective degradability $(\mathrm{g} / 100 \mathrm{~g})$ is calculated from in situ degradation using the step by step method (Kristensen et al., 1982) assuming a transit outflow rate of $6 \% / \mathrm{h}\left(\mathrm{ED}_{6}\right)$. It is possible to predict $E D$ from $E D_{6}$ as described by Sauvant and Nozière (2013).

The in vivo validation for nitrogen. For nitrogen, the BoviDig_PDI database was used for validation of the equation (5). The measured duodenal flow of non-microbial $C P$ $($ NMCPduo $=47.0 \pm 22.3, \min =11.6, \max =125.4 \mathrm{~g} / \mathrm{kg} \mathrm{DMI})$, that represents the sum of undegraded dietary $\mathrm{CP}$ and endogenous CP at duodenum, was used. It was compared to the duodenal flow of undegraded $\mathrm{CP}$ estimated from in situ data of ED_N calculated with equation (5) $(67.7 \pm 8.5, \min =39.9$, $\max =88.7 \%$ ), using a within-experiment regression (Figure 2a):

$$
\begin{gathered}
\text { NMCPduo }=14.2+0.96 \mathrm{CP}\left(1-0.01 \mathrm{ED} \_\mathrm{N}\right) \\
(n=311 ; n \exp =121 ; \mathrm{RSD}=8.8)
\end{gathered}
$$

The intercept of 14.2 is significantly different from 0 , and represents the duodenal endogenous CP (EndoCP, in $\mathrm{g} / \mathrm{kg} \mathrm{DMI})$. The slope of 0.96 of equation (6) does not differ from the value 1 (Student's test) and the 0.01 is applied as ED is expressed as a percentage. This validates the use of the equation 5 , which integrates the effects of $\mathrm{FL}$ and $\mathrm{PCO}$ on fractional passage rate applied to in situ data to provide an unbiased prediction of digestion of dietary proteins in the rumen. The following 
simplified equation can thus be retained to calculate the flows of rumen degraded protein (RDP, in $\mathrm{g} / \mathrm{kg} \mathrm{DM}$ ) and undegraded protein flowing at duodenum (RUP, in $\mathrm{g} / \mathrm{kg} \mathrm{DM}$ ):

$$
\begin{gathered}
\mathrm{RDP}=\mathrm{CP} 0.01 \mathrm{ED} \_\mathrm{N} \\
\mathrm{RUP}=\mathrm{CP}\left(1-0.01 \mathrm{ED} \_\mathrm{N}\right)
\end{gathered}
$$

The in vivo validation for starch. For starch, the BoviDig Starch database was used for validation of the equation (5). The measured duodenal flow of starch, that represents ruminally undegraded starch (RUSt $=102.2 \pm 49.6$, $\min =2.7$, $\max =280 \mathrm{~g} / \mathrm{kg} \mathrm{DMl}$ ) was compared to the duodenal flow of starch estimated from in situ data, calculated using equation (5) for ED_Starch $(72.8 \pm 8.1, \min =52.9$, $\max =90.6 \%$, using a within-experiment regression (Figure $2 \mathrm{~b}$ ):

$$
\begin{aligned}
\mathrm{RUSt} & =-3.95+1.08 \mathrm{Starch}\left(1-0.01 \mathrm{ED}_{-} \text {Starch }\right) \\
\quad(n & =283, n \exp =116, \mathrm{RSD}=22.1)
\end{aligned}
$$

The intercept does not differ from 0 and the slope does not differ from 1, moreover no effect of FL or PCO is observed on the residuals of this equation. As was the case for nitrogen, this validates the use of the equation 5 applied to in situ data
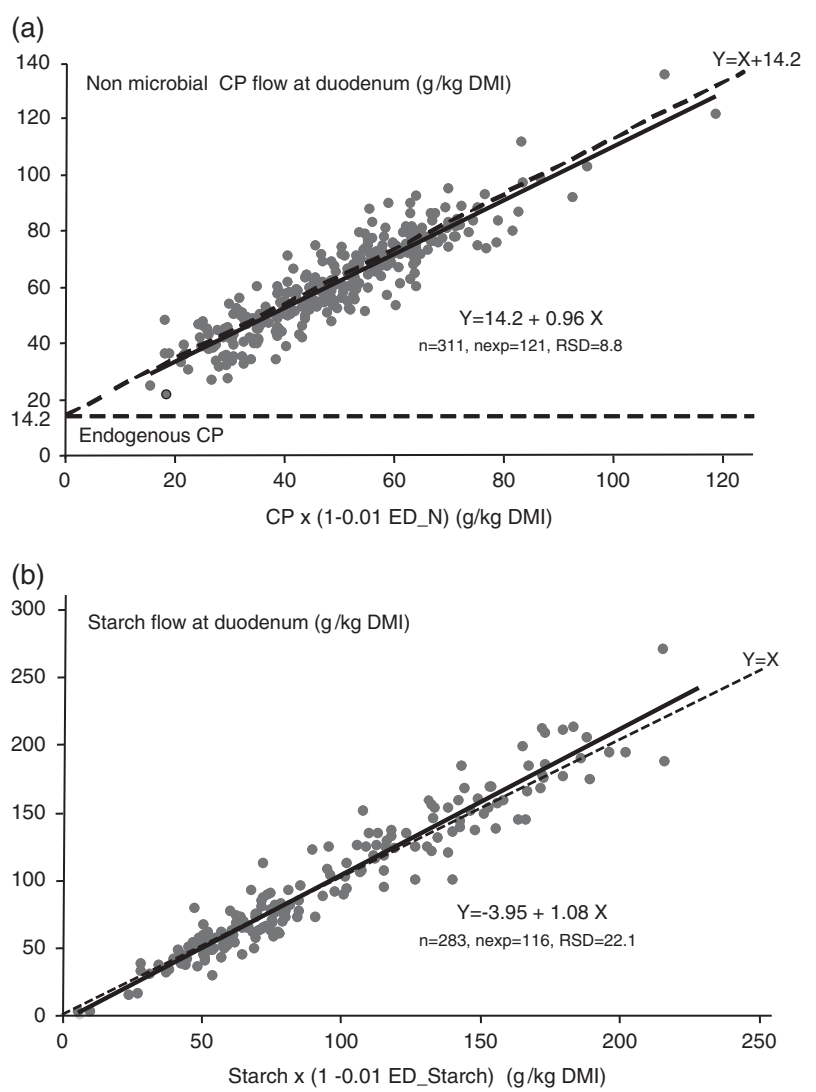

Figure 2 Intra-experiment relationship between (a) non microbial CP flow at duodenum and non-degradable CP in sacco (experiments focused on effects of quantity and quality of protein); (b) starch flow at duodenum and non-degradable starch in sacco (experiments focused on influence of quantity and quality of starch). to provide an unbiased prediction of digestion of starch in the rumen. However, equation (10) was much less accurate than equation (7). The following simplified equations can thus be retained to calculate the flow of starch at duodenum (RUSt, g/ $\mathrm{kg} \mathrm{DMI})$ and the flow of starch digested in the rumen (RDSt, $\mathrm{g} /$ kg DMI):

$$
\begin{gathered}
\mathrm{RUSt}=\operatorname{Starch}\left(1-0.01 \mathrm{ED} \_ \text {Starch }\right) \\
\mathrm{RDSt}=\text { Starch } \times 0.01 \mathrm{ED} \_ \text {Starch }
\end{gathered}
$$

Implications on feed values. The updated values of ED_N and ED_Starch of feedstuffs are now calculated using equation 5 . For a given feedstuff, the $a, b, k d$ values are considered to be constant (Sauvant et al., 2002). The fractional passage rates of particulate fractions of forages (kpf), concentrate $(\mathrm{kpc})$ and soluble phase $(\mathrm{ktl})$, are calculated using equations 1,2 and 3 , respectively. For tabulated values, it is assumed $\mathrm{FL}=\mathrm{FLref}$, and $\mathrm{PCO}=0$. For the values of the feed within a diet, we use the values of FL and PCO corresponding to the diet. These principles constitute a first justification that the nutritive value of a given feedstuff varies depending on the diet in which it is included.

\section{The rumen protein balance}

Definition and biological significance. The rumen protein balance (RPB, g/kg DMI) represents the difference between $C P$ intake and non-ammonia CP (i.e. undegraded dietary $\mathrm{CP}+$ microbial $\mathrm{CP}+$ endogenous $\mathrm{CP}$ ) flowing out at the duodenum.

$$
\mathrm{RPB}=\mathrm{CP}-(\mathrm{RUP}+\mathrm{Mic} \mathrm{CP}+\text { EndoCP })
$$

with RUP, MicCP and EndoCP defined according to equations (9), (41') and (7), respectively. Equation (12) can be rearranged into equation $\left(12^{\prime}\right)$ :

$$
\mathrm{RPB}=\mathrm{RDP}-\mathrm{Mic} C \mathrm{P}-\mathrm{EndoCP}
$$

The RPB is commonly measured using animals canulated at the duodenum. Across the overall BoviDig database, the measured values of RPB range between approximately -50 and $+100 \mathrm{~g} \mathrm{CP} / \mathrm{kg}$ DMI $(11 \pm 32 \mathrm{~g} / \mathrm{kg} \mathrm{DMI})$. It primarily, and linearly, depends on the dietary CP with CP ranging across diets from $<50$ to $>250 \mathrm{~g} / \mathrm{kg} \mathrm{DM}$. Within-experiment, the relationship is accurate:

$$
\begin{aligned}
& \mathrm{RPB}=-84.5+0.61 \mathrm{CP} \\
& \quad(n=735, n \exp =285, \mathrm{RSD}=8.6)
\end{aligned}
$$

This relationship illustrates that the dietary $\mathrm{CP}$ content corresponding to $\mathrm{RPB}=0$ is almost $140 \mathrm{~g} / \mathrm{kg} \mathrm{DM}$, and that when data are expressed on a DMI basis, on average $~ 60 \%$ of changes in $\mathrm{CP}$ intake do not reach the duodenum as nonNH3 CP. This accounts for the net balance between NH3 absorption and urea recycling through gut wall and saliva. Using 220 available experiments, it was found that RPB values have a large influence on the NH3-N content of the rumen fluid $(121.5 \pm 55.7, \min =5, \max =393 \mathrm{mg} / \mathrm{l})$, the 
within-experiment regression is:

$$
\begin{aligned}
& \mathrm{NH} 3-\mathrm{N}=105.2+1.45 \mathrm{RPB} \\
& \quad(n=570, n \exp =220, \mathrm{RSD}=20.8)
\end{aligned}
$$

Moreover, RPB expressed in N/kg DMI is the first factor accounting for urinary $\mathrm{N}$ losses (UN $9.2 \pm 3.5$, $\min =2.0$, $\max =23.5 \mathrm{in} \mathrm{g} / \mathrm{kg} \mathrm{DMl}$ ), as also observed in sheep and goats (Nozière et al., 2013).

$$
\begin{aligned}
& \mathrm{UN}=7.72+0.62 \mathrm{RPB} \_\mathrm{N} \\
& (n=109, n \exp =35, \mathrm{RSD}=1.0)
\end{aligned}
$$

In several systems (NRC, DVE/OEB, NorFor), the RPB is already used as an index of the difference between the microbial protein synthesis permitted from available degradable CP in the rumen and that permitted from energy extracted from rumen fermented organic matter. In these systems, recommendations to ensure that RPB is close to zero and not negative are provided. In the initial version of the PDI system, RPB was not used but a fairly similar quantity was the calculated index Rmic = (PDIN-PDIE)/UF (Agabriel et al., 2007), that is highly correlated to RPB, but is neither measurable nor additive. In Systali project, the RPB, that is additive and measurable, has been considered as a relevant criterion not only to assess the equilibrium between degradable $\mathrm{N}$ and available energy in the rumen, but also to integrate quantitative effects of energy $\times$ nitrogen interactions on digestive processes, and particularly on $\mathrm{OM}$ digestibility (OMd) and microbial growth (see following paragraphs). Moreover it will be used to predict $\mathrm{N}$ urinary losses.

Prediction. Given that in equation (12') the difference RDPMicCP reflects the degradable CP that is not recovered as microbial CP, RPB can be calculated from the criteria of the PDI system:

$$
\mathrm{RPB}=-14.2+(\text { PDIMN }-\mathrm{PDIME}) /(0.8 \times 0.8)
$$

where PDIMN and PDIME are the digestible microbial protein when nitrogen and energy are limiting, respectively, assuming that microbial protein accounts for 0.8 of MicCP, and is digested at $80 \%$. Due to the endogenous CP at the duodenum of $14.2 \mathrm{~g} / \mathrm{kg}$ DMI (cf equation (7)), the strict equilibrium between energy and nitrogen supply to microbes for microbial synthesis in the rumen is not obtained when $R P B=0$, but when RPB $=-14.2 \mathrm{~g} / \mathrm{kg}$ DM. The external evaluation of equation (12") on the database OviDig (34 exp, 102 trt) shows an unbiased prediction of actually measured RPB (Nozière et al., 2013).

\section{The digestive interactions}

Definition and implication in current feed evaluation systems. The phenomena of digestive interactions have long been known in ruminants. They are responsible for the non-additivity of feed values (FV) of feedstuffs within a ration:

$$
\mathrm{FV}_{r}=\Sigma i\left(\mathrm{FV}_{i} \times \mathrm{P}_{i}\right) \pm \mathrm{DI}
$$

where $\mathrm{FV}_{r}$ is the feed value of the ration, $\mathrm{FV}_{i}$ is the feed value of the feedstuff $i, \mathrm{P}_{i}$ is the proportion of the feedstuff $i$ within the ration $\left(\Sigma_{i} P_{i}=1\right)$, and $\mathrm{DI}$ is the term for the digestive interaction that can be negative or positive. A first challenge was to identify the main factors involved in these digestive interactions, to quantify their respective effects, and to include them in a model that is compatible with a feed evaluation system.

Current FUS for ruminants use different ways to account for these digestive interactions. In the NRC (2001), a multiplicative factor (discount factor) based on the level of production is applied to the digestibility of the diet (Total Digestible Nutrient, TDN). In NorFor (Volden, 2011), the interaction is calculated with a mechanistic model of cell wall digestion in the rumen. In the FiM system, a global interaction was directly applied at the level of metabolizable energy (Thomas, 2004). It appears that the FUS used in Finland (http://www.mtt.fi/rehutaulukot/) offers the most advanced model, and considers respectively influences of the $\mathrm{FL}$, the dietary energy content, the proportion of concentrate and the CP content of the ration, quantified from metaanalyses of many literature data (Huhtanen et al., 2009; Nousiainen et al., 2009). So far, in the INRA net energy system (UF), digestive interactions were taken into account through an overall correction of the NE value of the ration for dairy cows (Faverdin et al., 2007), or of the NE requirements for the dairy goats (Sauvant et al., 2007). This correction has been derived from feeding trials without measurement of any digestibility (Vermorel et al., 1987; Vermorel and Coulon, 1998), moreover no impact of digestive interactions have so far been taken into account in the INRA MP system (PDI).

Evaluation of digestive interactions on organic matter digestibility. Given that the $\mathrm{OMd}$ is the major component of $\mathrm{NE}$ value and microbial protein supply, and that it can easily be measured in vivo and/or predicted from chemical composition of feedstuffs or from laboratory methods, it is systematically indicated in feed tables associated to the INRA feed evaluation systems. Consequently, OMd appeared as the best measure of feed value and thus the best criteria with which to assess digestive interactions. According, equation (17) was derived from equation (16) by substituting OMd for FV.

$$
\Delta \mathrm{OMd}=\left[\Sigma_{i}\left(\mathrm{OMd}_{i} \times \mathrm{POM}_{i}\right)\right]-\mathrm{OMdm}
$$

$\Delta \mathrm{OMd}$ is the digestive interaction, $\mathrm{OMd}_{i}$ is the tabulated $\mathrm{OMd}$ of the feedstuff $i, \mathrm{POM}_{i}$ is the proportion of OM of the feedstuff $i$ into the dietary $\mathrm{OM}\left(\Sigma, \mathrm{POM}_{i}=1\right)$, and $\mathrm{OMdm}$ is the $\mathrm{OMd}$ of the ration actually measured in vivo. With this expression, $\Delta \mathrm{OMd}>0$ when $\mathrm{DI}<0$, and reciprocally.

The digestive interactions on OMd mainly occur at the ruminal level; using the BoviDig database they appeared to be related to three major causes: (i) an increased passage rate of digesta that reduces availability of substrates to microorganisms when intake increases; (ii) a decreased pH that inhibits cellulolytic microorganisms when the proportion of concentrate in the diet increases; (iii) a change in microbial activity depending on nitrogen availability. The principle of 
the approach has been to study and quantify the effects of $\mathrm{FL}, \mathrm{PCO}$ and RPB on $\triangle \mathrm{OMd}$ (i.e. the difference, for the same rations, between OMd calculated by additivity from INRA feed tables, and OMdm actually measured in vivo) through three sub-databases pooling experiments respectively focused on the influences of FL, PCO and RPB.

Effect of FL. To quantify the effect of FL on OMd, data from digestibility trials in which the experimental factor was the FL of the same diet were extracted from BoviDig and Rumener databases. To overcome the differences between species, the FL was expressed as \% of BW and not BW ${ }^{0.75}$ (Sauvant et al., 2006). Statistics were the following for OMd $(70.9 \pm 7.2$, $\min =45.8, \max =87.3)$ and $\mathrm{FL}(1.7 \pm 0.7, \min =0.4$, $\max =4.0$ ), and a within-experiment regression (Figure 3a) was calculated:

$$
\begin{aligned}
& \text { OMdm }=76.0-2.74 \mathrm{FL} \\
& \quad(n=400, n \exp =152, \mathrm{RSD}=1.6)
\end{aligned}
$$

The very low RSD compared to the precision of in vivo OMd measurement (Charlet-Lery, 1969) emphasizes the good quality of the present relationship. A comparable equation was already proposed by Sauvant and Giger-Reverdin (2009). The negative slope illustrates the effect of the increased digesta passage rate when FL increases, as discussed previously. This slope is lower than the corresponding slope proposed by Weiss (1998) and used in the NRC (2001). The slope of the equation (18) was not affected either by the CP content, or by the average OMd of the diets. In contrast, NRC (2001) assumed that the response of TDN to FL increased with the average TDN value of the diet, but this was established on only 17 treatments.

Assuming that for a given feedstuff, the tabulated OMd has been measured at its reference $\mathrm{FL}$ (as discussed previously), the $\Delta \mathrm{OMd}$ related to $\mathrm{FL}\left(\Delta \mathrm{OMd} \_\mathrm{FL}\right)$ can be calculated as:

$$
\Delta O M d \_F L=2.74(F L-F L r e f)
$$

Effect of proportion of concentrate. To quantify the effect of PCO on digestive interactions ( $\triangle \mathrm{OMd} C \mathrm{CO})$, data from digestibility trials where the PCO varied a lot within-experiment, were extracted from the BoviDig_PDI database. $\triangle \mathrm{OMd}$, that represents $\triangle \mathrm{OMd} \_\mathrm{CO}$ with this data set, was calculated. The within-experiment regression (Figure 3b) was then estimated as:

$$
\begin{array}{r}
\Delta \mathrm{OMd}_{-} \mathrm{CO}=6.5 /\left(1+(0.35 / \mathrm{PCO})^{3}\right) \\
(n=72, n \exp =30, \mathrm{RSD}=1.2)
\end{array}
$$

This relationship was not affected by any other factors of interaction hidden in the between experiment variability. Again, RSD was low compared to the precision of OMd measurements. This equation (20) illustrates that calculation of OMd from tabulated data assuming additivity of DOM of feed tables leads to an overestimation of the actual OMd of diets with high $\mathrm{PCO}$, with a theoretical maximal interaction effect of 6.5 points when $P C O=1$. It also illustrates that
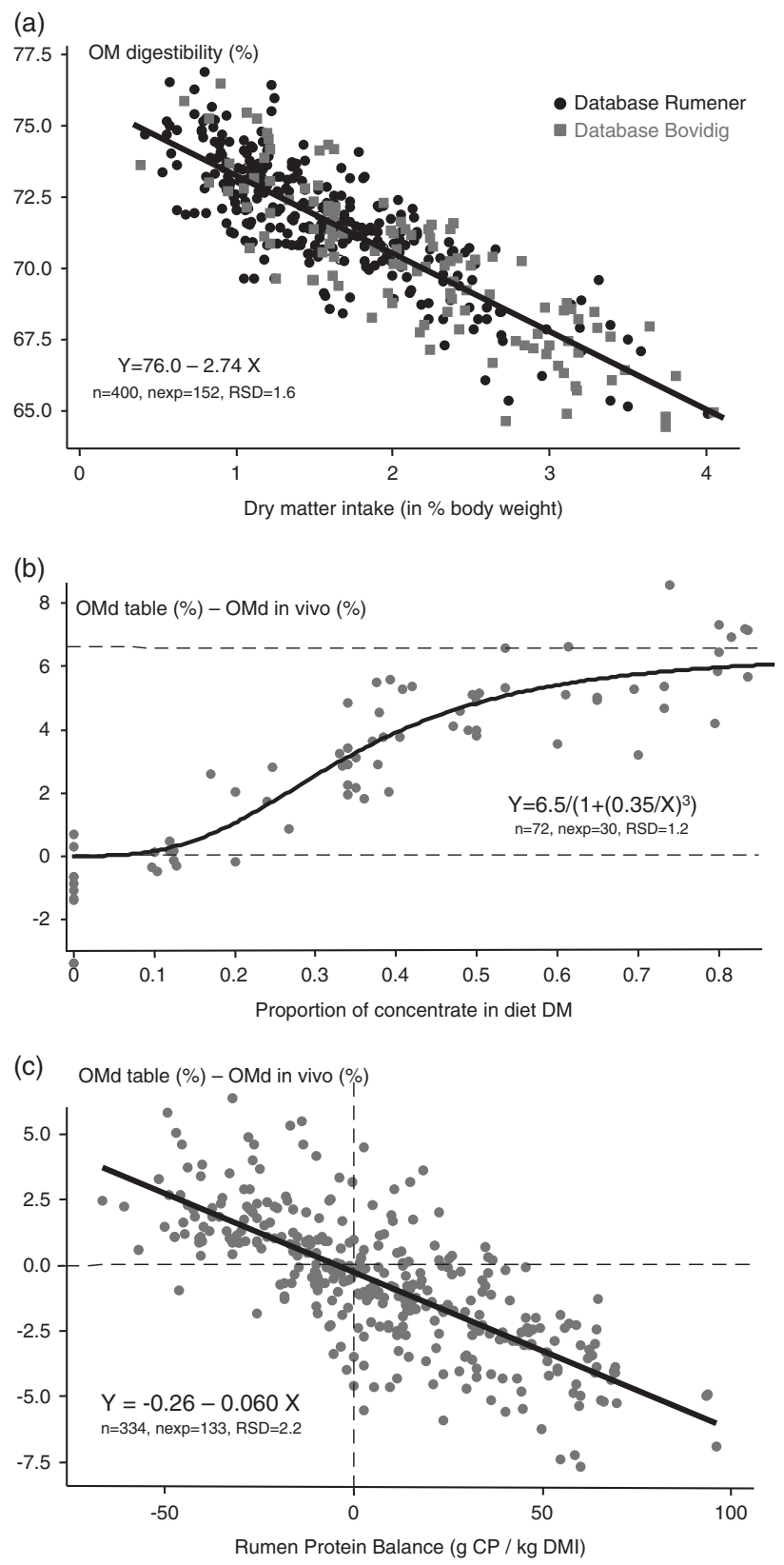

Figure 3 Intra-experiment relationship between (a) dry matter intake and OM digestibility of the diet (experiments focused on influence of feeding level); (b) proportion of concentrate in the diet and the difference between OM digestibility (OMd) calculated from tables INRA (2007) and actual in vivo OMd (experiments focused on influence of level of concentrate); (c) rumen protein balance (RPB) and the difference between OM digestibility (OMd) calculated from tables INRA (2007) and actual in vivo OMd.

when PCO $>0.4$, the marginal effect of an increase in PCO is less marked, probably due to the stabilization of the new balance in the ruminal ecosystem and/or to the low proportion of forage, which is the main component of the diet affected by this interaction.

Effect of the rumen protein balance. To quantify the effect of $\mathrm{RPB}$ on $\mathrm{OMd}$, data from digestibility trials where the experimental factor was the dietary level of degradable $C P$ were extracted from the BoviDig_PDI database. The digestive 
interaction on OMd due to RPB ( $\triangle \mathrm{dMO}$ RPB) was calculated as $\triangle O M d$ (equation (17)) corrected for the concomitant effects of FL (equation (19)) and PCO (equation (20)):

$$
\Delta \mathrm{OMd}_{\_} \mathrm{RPB}=\Delta \mathrm{OMd}-\Delta \mathrm{OMd}_{-} \mathrm{FL}-\Delta \mathrm{OMd}_{-} \mathrm{CO}
$$

The within-experiment regression (Figure $3 c$ ) was then calculated:

$$
\begin{aligned}
& \Delta O M d \_R P B=-0.26-0.060 \mathrm{RPB} \\
& \quad(n=334, n \exp =133, \mathrm{RSD}=2.2)
\end{aligned}
$$

This relationship, with an intercept that does not differ from 0 , and which is linear across the large range in RPB (from approximately -50 and $+100 \mathrm{~g}(\mathrm{CP} / \mathrm{kg} \mathrm{DMI})$ indicates that with diets deficient in RDP $(\mathrm{RPB}<0)$, the OMd value calculated by additivity from INRA feed tables overestimates measured OMd, whereas the opposite trend occurs for diets rich in RDP (RPB $>0$ ). With urea-supplemented low $\mathrm{N}$ diets, this effect on OMd appears limited to RPB $<20$ (Chapoutot et al., 2013b). Based on this relationship (equation (22)), it becomes possible to account for the effects of energy $x$ protein interactions in the rumen on OMd. So far, only the recent Finnish FUS system includes such an effect, based on the CP content of the diet. Both corrections based on CP according to the Finnish system, or based on RPB according to the present approach, have globally a similar impact on the NE of diets.

In practice, each feedstuff will be characterized in tables by a reference RPB (RPBref, in $\mathrm{g} C P / \mathrm{kg} \mathrm{DM}$ ), representative of $\mathrm{RPB}$ during the in vivo measurement of $\mathrm{OMd}$ retained for the tables. Within a diet, $\triangle O M d$ RPB of each ingredient is thus indexed on the difference between RPB of the diet and RPBref.

$$
\left.\Delta \mathrm{OMd} \_\mathrm{RPB}=-0.060 \text { (RPB }-\mathrm{RPBref}\right)
$$

For corn silage and straws RPBref is assumed to be 0 , because tabulated OMd measurement for these materials was carried out using urea $\mathrm{N}$ supplementation to compensate for the deficit in RDP. If these forages are given alone or with insufficient RDP supplementation, there is a decrease of -0.06 OMd per $g$ of decrease of RPB compared to the tabulated OMd value. This principle could be applied to all forages that are of low protein content $(\mathrm{RPB}<0)$ if it is certain that tabulated in vivo $\mathrm{OMd}$ measurement has been made with the right level of RDP supplementation. If it is not the case, it is possible to predict from equation (23), assuming RPBref $=R P B$ calculated according to equation (12"), the potential gain in OMd expected from a given protein supplementation. For all other forages, tabulated OMd is determined in vivo using the forage given alone, thus RPBref $=$ RPB (with RPB calculated according to equation $\left(12^{\prime \prime}\right)$ ). For concentrate and byproducts, it is necessary to associate a forage and at least two levels of inclusion to measure $\mathrm{OMd}$. The procedure used varies in terms of the forage/concentrate ratio and the nature of forage, but all procedures tend to converge towards approximately RPBref $=0.3 \mathrm{RPB}$ (with RPB calculated according to equation $\left(12^{\prime \prime}\right)$ ) which corresponds approximately to a dietary CP content comprised between 120 and $180 \mathrm{~g} / \mathrm{kg}$ DM for OMd measurement. Therefore, this value of RPBref $=0.3$ RPB was applied for all concentrates and by-products. With this way of calculation, $\triangle O M d \_R P B$ is globally and curvilinearly related to RBP, reaching a plateau corresponding to a maximum of 2 points of $\mathrm{OMd}$.

Additivity of the effects. The additivity of effects related to the application of the equations (19), (20) and (23) was assessed on the 346 treatments from the BoviDig_PDI data set. With this data set, $\triangle \mathrm{OMd} \_F L, \Delta O M d \_C O$ and $\triangle$ OMd_RPB averaged $4.1,3.9$ and -0.9 , respectively, reflecting that $\mathrm{FL}$ and concentrate proportions are the main causes of digestive interaction encountered in practice. The OMd of the ration was calculated (OMdc) from feed tables and application of interactions, assuming their additivity:

$$
\mathrm{OMdc}=\left[\Sigma_{i}\left(\mathrm{OMd}_{i} \times \mathrm{POM}_{i}\right)\right]-\Delta \mathrm{OMd}
$$

with $\Delta \mathrm{OMd}=\Delta \mathrm{OMd} \_\mathrm{FL}+\Delta \mathrm{OMd}_{-} \mathrm{CO}+\Delta \mathrm{OMd} \_\mathrm{RPB}$

The relationship between predicted OMdc and the measured OMdm did not significantly differ from $1(Y=X)$, with a RSD of 4.6 , which was reduced to 2.2 when the experiment effect is taken into account (Figure 4). This means that in practice the interactions can be calculated and applied separately, and can be considered as additive. The external evaluation of the equation (24) from OviDig (83 exp, 234 trt) and Caprinut (128 exp, $381 \mathrm{trt}$ ), shows an unbiased prediction of variation in actually measured OMd, but suggests that $\triangle \mathrm{OMd} \_\mathrm{CO}$ needs to be slightly attenuated for application of small ruminants (Nozière et al., 2013).

\section{The organic matter fermented in the rumen (FOM)}

Evaluation in current FUS, and limitations. The prediction of the $\mathrm{OM}$ truly digested in the rumen (OMtDR, $\mathrm{g} / \mathrm{kg} \mathrm{DMI})$ is a key issue in the future of FUS for ruminants. Indeed, OMtDR not only supports the production of microbial protein, that is a major source of AA for the host, but also conditions the loss in energy as $\mathrm{CH} 4$, and the supply of volatile fatty acids to the host. The OMtDR can be experimentally measured in vivo, but due to the relative imprecision, the difficulty and the cost

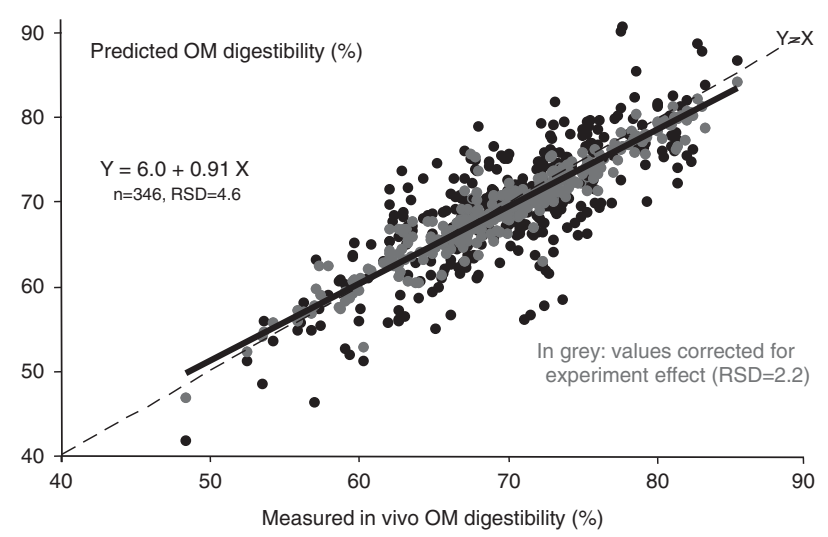

Figure 4 Relationship between measured and calculated OM digestibility taking into account the three digestive interactions. 
of such measurements, more simple criteria more or less representative of OMtDR are actually used in FUS.

In the first version of the PDI system, the digestible OM in the total tract (DOM), that was already well documented as it is the main component of the NE value, was taken as a predictor of OMtDR (INRA, 1978), and this principle has also been used in other systems, particularly the NRC (2001). In the first revision of the PDI system (Vérité et al., 1987), the FOM was defined as the DOM minus the fractions of DOM that are not fermented in the rumen, that is fermentation products of silage (FP), crude fat (estimated by ether extract) and the fraction of CP undegraded in situ (RUP, calculated using $\mathrm{ED}_{6} \mathrm{~N}$ ). This principle was also adopted in the $\mathrm{OEB} /$ DVE system (Tamminga et al., 1994), that also subtracted the fraction of starch undegraded in situ (RUSt, calculated using $E_{6}$ St). This last principle has also been applied in INRA feed tables since 2002 (INRA-AFZ, 2002). Despite these revisions, the actual OMtDR remained inaccurately predicted by these derivations from FOM, due to several simplifications in the hypotheses of calculation, namely: (i) the ruminal passage rate of $\mathrm{CP}$ and Starch was supposed constant, and RUP and RUSt were assumed to be totally digestible in the intestines; (ii) CF was assumed to be totally indigestible in the rumen and totally digestible in the intestines; (iii) digestible NDF was assumed to be totally digested in the rumen; (iv) the OMD that does not account for $\mathrm{CP}$, starch, NDF, CF or FP, was assumed to be totally fermented in the rumen; (v) no digestive interactions were integrated in the calculation of OMD.

Other FUS (CNCPS, NorFor, FiM) estimated OMtDR using an approach based on summation of rumen degraded fractions, estimated with the in situ approach. Despite being more mechanistic and a priori more dynamic, the main limitations of this approach is the small number of publications with in situ degradation of NDF, moreover this criteria is very sensitive to the ruminal environment, as discussed previously. This limitation is not negligible given the high contribution of NDF digestion in the rumen to the OMtDR ( $35 \pm 21 \%$ on 492 treatments in BoviDig).

A new proposal to calculate FOM. In the Systali project, the basic principle of basing FOM on the subtraction from DOM of the digestible but non fermented fractions, already adopted by INRA since 1988, was maintained. However, given the limits described above, new proposals have been developed to refine the quantification of each fraction involved in the following generic equation:

$$
\begin{aligned}
\mathrm{FOM}= & \mathrm{DOM}-\mathrm{DOMint}-\mathrm{FP}=\mathrm{DOM} \\
& -\Sigma \mathrm{a}_{i} \times\left(\mathrm{Fduo}_{i}-\mathrm{Ffec}_{i}\right)-\mathrm{FP}
\end{aligned}
$$

This equation relates the $\mathrm{OM}$ fermented in the rumen (FOM), apparently digested in the total tract (DOM), digested in the intestines (DOMint), the duodenal flows (Fduo ${ }_{i}$ ) and the faecal flows $\left(\mathrm{Ffec}_{i}\right)$ of the components $i$ (dietary $\mathrm{CP}$, starch, NDF, fatty acids). For each fraction, the coefficients $a_{i}$ were statistically compared to 1 (see below).
OM apparently digested in the total tract. This is calculated from $\mathrm{OM}$ and $\mathrm{OMd}$ as defined in equation (24), and thus accounts for digestive interaction.

$$
\mathrm{DOM}=\mathrm{OM} \times 0.01 \mathrm{OMd}
$$

Dietary CP apparently digested in the intestines. This fraction was considered to be quantitatively close to the dietary CP truly digested in the small intestines with a true digestibility of $\mathrm{dr}(\%)$, thus it was equated with the PDIA (alimentary protein digestible in the intestines) fraction.

$$
\text { Dietary CPDint } \approx \mathrm{PDIA}=\mathrm{CP}\left(1-0.01 \mathrm{ED} \_\mathrm{N}\right) \cdot 0.01 \mathrm{dr}
$$

Starch apparently digested in the intestines. This fraction (StDint $=80.0 \pm 55.0, \min =1.2, \max =267.1 \mathrm{~g} / \mathrm{kg} \mathrm{DM}$ ) mainly depends on the duodenal flow of starch. Data from digestion trials reporting duodenal and fecal flows of starch were extracted from the BoviDig_starch database. The within-experiment regression was then calculated:

$$
\begin{aligned}
& \text { StDint }=0.21+0.826 \text { RUSt } \\
& \quad(n=375, n \exp =144, \text { RSD }=4.4)
\end{aligned}
$$

Given that the intercept does not differ from 0 , and that in situ data provide an unbiased prediction of RUSt (cf equations $(10)$ and $\left.\left(10^{\prime}\right)\right)$, StDint can be directly calculated from ED_Starch:

$$
\text { StDint }=0.826 \text { Starch }(1-0.01 \text { ED_Starch })
$$

NDF apparently digested in the intestines. As discussed below, we assumed that duodenal flow of NDF could not be accurately predicted from in situ data. In contrast, given that the fecal NDF (NDNDF $=174.3 \pm 56.1, \quad \min =32.6$, $\max =468.9 \mathrm{~g} / \mathrm{kg} \mathrm{DM}$ ) accounts for a large part of fecal OM, prediction of intestinal digestion of NDF was assessed from OMd. Data from digestion trials reporting duodenal and/or fecal flows of NDF and OM were extracted from the BoviDig database. The within-experiment regression (Figure 5) was then calculated:

$$
\begin{aligned}
& \text { NDNDF }=591-6.090 \mathrm{Md} \\
& \quad(n=1170, n \exp =459, \mathrm{RSD}=13)
\end{aligned}
$$

The slope of the equation (30) was very stable $(-7.03$ $v$ v. -6.09$)$ when only treatments corresponding to $100 \%$ forage diets were considered $(n=118)$. With a set of 91 treatments on sheep fed $100 \%$ temperate forage diets, Baumont et al. (2007) reported a slope of -8.63 . With a set of 752 treatments on ruminants fed tropical diets (Assoumaya et al., 2007), a slope of -8.45 was obtained. Despite slight differences in slopes between these equations, all lead to very similar results when they were applied to their respective range of validity.

The flow of NDF at the duodenum (NDFduo $=198.1 \pm$ 59.7, $\min =56.5, \max =463.4 \mathrm{~g} / \mathrm{kg} \mathrm{DM}$ ) can be accurately predicted from NDNDF with a slope not different from 1:

$$
\begin{aligned}
& \text { NDFduo }=11.4+1.08 \text { NDNDF } \\
& \quad(n=591, n \exp =225, \text { RSD }=13)
\end{aligned}
$$




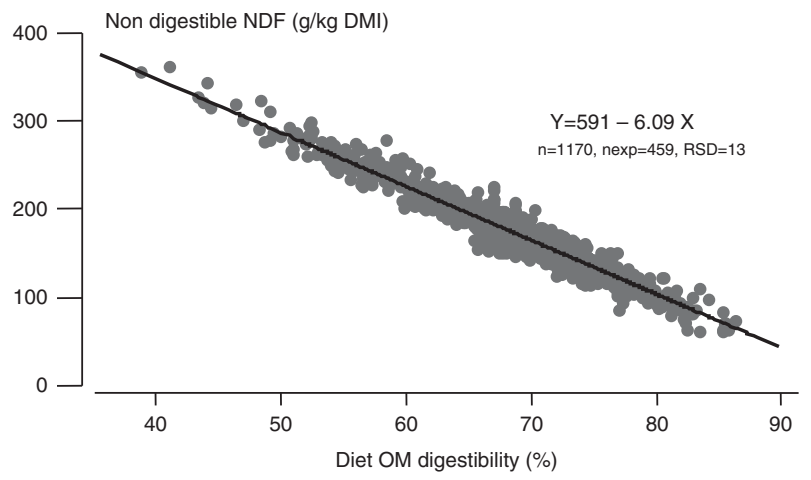

Figure 5 Intra-experiment relationship between OM digestibility and the non-digestible NDF content of the diet.

The intestinal digestion of NDF is then calculated from equations (30) and (31):

$$
\text { NDFDint }=\text { NDFduo }- \text { NDNDF }
$$

Fatty Acids apparently digested in the intestines. The prediction of total FA at the duodenum (FAduo $=46.5 \pm 19.7$, $\min =14.2, \quad \max =101.5 \mathrm{~g} / \mathrm{kg} \quad \mathrm{DM}) \quad$ and apparently digested in the intestines (FADint $=33.7 \pm 11.7, \min =13.9$, max $=61.3 \mathrm{~g} / \mathrm{kg}$ DM) are based on equations already published by Schmidely et al. (2008). These equations have been derived by meta-analysis (Glasser et al., 2008; Schmidely et al., 2008). The database used concerned digestion trials where intake, duodenal and fecal flows of FA were measured in experiments where dietary FA $(=44.5 \pm 20.5$, $\min =9.1, \max =99.4 \mathrm{~g} / \mathrm{kg} \mathrm{DM}$ ) was an experimental factor. The within-experiment regressions were then calculated:

$$
\begin{aligned}
& \text { FAduo }=9.7+0.75 \text { FA } \\
& \quad(n=194, n \exp =60, \text { RSD }=3.6) \\
& \text { FADint }=6.0+0.599 \text { FAduo } \\
& \quad(n=136, n \exp =40, \text { RSD }=3.0)
\end{aligned}
$$

The high value of the intercept of equation (33) can be interpreted as the microbial FA flow at duodenum. It is known that rumen microbes, particularly attached bacteria, are rich in lipids (Bauchart et al., 1990). The total FA content of concentrates and by-products can be calculated from their ether extract (EE), considering $F A=a E E$, with $0.45<a<0.90$ depending on the feedstuff (INRA-AFZ, 2002). For forages, the FA content can be predicted from their CP content, according to Glasser et al. (2013) and Maxin et al. (2013).

Evaluation of the new proposal. This new proposal is based on the hypothesis that the summation of dietary fractions apparently digested in the intestines corresponds to the differences between measured DOM and OMtDR (cf equation (26)). To evaluate this assumption, for each of the four fractions digested in the intestines (FracDint, i.e. PDIA, StDint, NDFDint, and FADint), we calculated the slope of the following within-experiment relationship, using data from experiments specifically focused on the dietary content or
Table 1 Within-experiment relationships between the measured digested OM not accounting for OM truly digested in the rumen ([DOMm - OMtDR], in $\mathrm{g} / \mathrm{kg} D M)$ and the dietary fractions digested in the intestines (FracDint, in $\mathrm{g} / \mathrm{kg}$ DM)

\begin{tabular}{lccrcr}
\hline \hline FracDint & Intercept a & Slope b & $n \exp$ & $n$ & RSD \\
\hline PDIA & 90.0 & 1.04 & 74 & 179 & 29.7 \\
StDint & 14.1 & 1.11 & 66 & 145 & 27.0 \\
NDFDint & 74.9 & 0.96 & 170 & 418 & 26.7 \\
FADint & 129.8 & 1.18 & 17 & 38 & 20.3 \\
\hline \hline
\end{tabular}

Relationships established using data from experiments specifically focused on the dietary content of considered fraction: $D O M m-O M t D R=a+b$ FracDint (cf equation (35)).

quality of the considered fraction (N, starch, NDF and FA, respectively):

$$
(\mathrm{OM} \times \text { OMdm } \cdot 0.01)-\mathrm{OMtDR}=\mathrm{a}+\mathrm{b} \text { FracDint }
$$

For the four relationships which correspond to the four fractions, slopes did not differ from 1 (Table 1), showing that FOM can be predicted by subtracting from DOM the dietary fractions digested in the intestines:

$$
\begin{aligned}
\text { FOM }= & \text { DOM }- \text { PDIA }- \text { StDint } \\
& - \text { NDFDint }- \text { FADint }- \text { FP }
\end{aligned}
$$

The external evaluation of the equation $\left(26^{\prime}\right)$ from OviDig (27 exp, 84 trt) shows an unbiased prediction of variation in actually measured OMtDR (Nozière et al., 2013).

\section{The production of volatile fatty acids in the rumen}

As the renewed calculation of FOM (equation $\left(26^{\prime}\right)$ ) allows a consistent estimation of in vivo OMtDR, it becomes possible to calculate the production of volatile fatty acids (VFA) from FOM. Indeed, given that OM apparently digested in the rumen (OMaDR $=\mathrm{OMtDR}-$ microbial $\mathrm{OM})$ accounts for VFA and gas, and that partition of C between VFA and gas depends largely on the laws of stoichiometry and of thermodynamic, total VFA production (TVFAProd, in $\mathrm{mol} / \mathrm{kg}$ DMI) can be estimated using the BoviDig database from measured OMaDR and VFA molar proportions in the rumen, as described by Nozière et al. (2011). This leads to an average ratio of $8.35 \pm 1.21 \mathrm{~mol}$ total VFA $/ \mathrm{kg}$ OMtDR, with this ratio being negatively affected by PCO $(-1.1 \mathrm{~mol}$ VFA/kg OMtDR when PCO increases from 0 to 1 ), which is consistent with the positive effect of $\mathrm{PCO}$ on microbial growth from OMtDR (cf equation (41)):

$$
\text { TVFAProd }=8.35-1.1(\text { PCO }-0.43) \times 0.001 \text { FOM }
$$

Moreover a set of equations was proposed to calculate the VFA molar percentages of acetate, propionate, butyrate and minor VFA from the ratio of digestible NDF/digestible OM, the ruminal starch digestibility and the level of DMI (tables 3 to 5 in Nozière et al. (2011). All the dietary and ruminal criteria used for these predictions can be obtained from equations presented in the present text. 


\section{The production of microbial proteins}

Evaluation in current FUS, and limitations. The production of microbial CP (MicCP) has always been a sticking point of FUS due to the uncertainty of measurements, and to the difficulty in extracting the main sources of variation from a limited number of experiments. In the PDI system, MicCP was first considered equal to $120 \mathrm{~g} / \mathrm{kg}$ DOM (INRA, 1978), then to $145 \mathrm{~g} / \mathrm{kg}$ FOM (Vérité et al., 1987). Other FUS adopted quite similar assumptions: $130 \mathrm{~g} / \mathrm{kg}$ TDNcor in the NRC (2001), $150 \mathrm{~g} / \mathrm{kg}$ FOM in the Dutch DVE/OEB (Tamminga et al., 1994). All these estimates represent an average value which, apart from the FOM, ignores the effects of other factors known to affect the efficiency of microbial growth. Some of them have been incorporated in recent proposals. In NorFor, based on a previous meta-analysis by Archimède et al. (1997), the fermented substrates (starch, NDF, proteins and other carbohydrates) are assumed to have a differential efficiency of transformation into MicCP. In FiM (Thomas, 2004) it was assumed that the efficiency of substrate use for microbial growth was driven by the pattern of rumen fermentation and it was different for small particles, particles of concentrate and of forage. In DVE/OEB ${ }_{2011}$, the system is much more detailed, the calculation involves 21 different substrates differing according to the nature of the constituents (proteins, starch, soluble sugars, NDF), the nature of the feedstuff (forage $v$. concentrate) and the types of fractions (soluble $v$. degradable $v$. non-degradable). For each of these fractions, the fractional passage rates and efficiency of transformation in MicCP are considered to be different (Van Duinkerken et al., 2011). A major limitation of these approaches, a priori more mechanistic than previous proposals, is their degree of complexity given that an increased accuracy in predicting MicCP in this way has not yet been demonstrated. In the present study, we did not consider the yield of ATP transferred from FOM into microbial mass (YATP concept), even though this has been integrated in recent systems (Thomas, 2004; Van Duinkerken et al., 2011). The reason for our choice is that taking ATP into account leads to a substantially more complicated system based on parameters which are often not accurately known (i.e. maintenance ATP requirement of microbes), and thus do not guarantee an improved accuracy at the level of applications. In the Systali project, we have tried to build a 'top-down' prediction that is less analytical but integrates key factors that have been experimentally demonstrated, and leads to a more accurate prediction.

Factors causing variation in the production of microbial protein. In the Systali project, we assumed that OMtDR, which represents the energy available for microorganisms, is the main factor responsible for microbial growth. To quantify this effect, data from digestion trials reporting both OMtDR $(543 \pm 110, \min =253, \max =880 \mathrm{~g} / \mathrm{kg} \mathrm{DM})$ and MicCP $(83.8 \pm 26.0, \min =17.1, \max =174.3 \mathrm{~g} / \mathrm{kg} \mathrm{DM})$ measurements were extracted from the BoviDig database. The withinexperiment regression was then calculated:

$$
\begin{aligned}
& \mathrm{MicCP}=45.2+73.31 \times 10^{-3} \mathrm{OMtDR} \\
& \quad(n=707, n \exp =270, \mathrm{RSD}=7.6)
\end{aligned}
$$

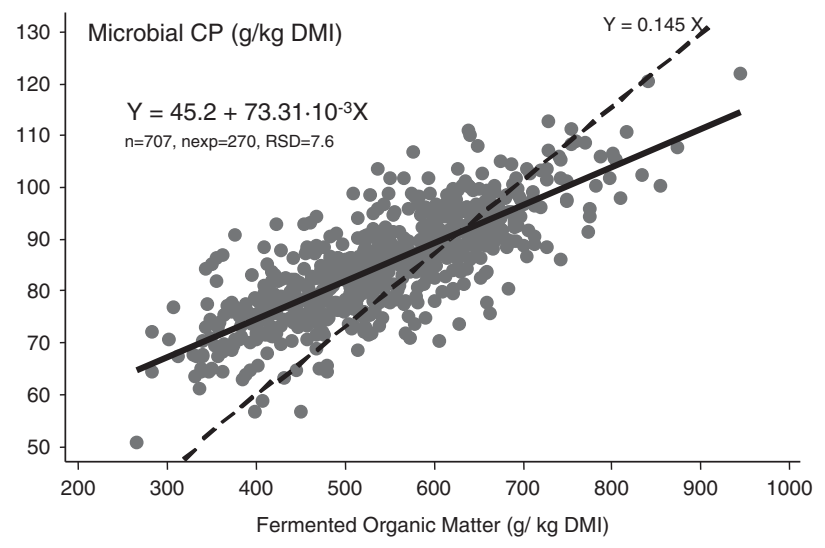

Figure 6 Intra-experiment relationship between microbial CP production and the fermented $\mathrm{OM}$ in the rumen.

This relationship (Figure 6), exhibits a positive intercept that differs from 0 , and a slope that is half that used in the previous PDI or DVE/OEB systems. This shows that in these systems, the hypothesis of a constant efficiency of the transformation of FOM to MicCP leads to underestimation of microbial synthesis with low levels of FOM, and vice versa at high levels of FOM. This effect could be the outcome of more efficient recycling or better conditions of $\mathrm{pH}$ in the rumen of animals receiving diets with low OMtDR.

We investigated whether components of the OMtDR could influence the relationship between OMtDR and MicCP, as has been proposed in the newly revised DVE/OEB 2011 (Van Duinkerken et al., 2011) and in NorFor (Volden, 2011). To do this, in a first step the measured OMtDR was separated into three fractions: (i) the fermentable CP (FCP = NMCPduo-EndoCP), which is the smallest and the less variable fraction $(200 \pm 60 \mathrm{~g} / \mathrm{kg} \mathrm{DM})$; (ii) the NDF digestible in the rumen (NDFDru = NDF-NDFduo, $350 \pm 200 \mathrm{~g} / \mathrm{kg} \mathrm{DM}$ ); (iii) and the residual OMtDR (resOMtDR $=0 M t D R-F(P-N D F D r u)$, which is the largest fraction $(450 \pm 220 \mathrm{~g} / \mathrm{kg} \mathrm{DM})$ and mainly accounts for easily fermentable carbohydrates in the rumen. Both resOMtDR and NDFDru are closely and negatively correlated (inter- as well as within-experiment). This illustrates the substitution of these two major fractions across the wide variety of diets that precludes an easy statistical separation into their respective effects on microbial synthesis. However, using a within-experiment multiple regression approach including these three fractions, MicCP appeared to be mainly related to resOMtDR, and at a lesser extent to FCP, but not to NDFDru. These data confirm the influence of the nature of the fermented substrate to sustain microbial growth (Archimède et al., 1997). In particular, it confirms the lower efficiency of proteins compared to carbohydrates for sustaining microbial growth, a factor already included in the FiM system (Thomas, 2004). This underlines the dominant role of easily fermentable carbohydrates, and the very limited role of fermented NDF, to support microbial growth. In contrast, if NDFDru is replaced by NDFduo, the role of cell wall constituents to carry attached microbes out 
of the rumen can be clearly shown:

$$
\begin{aligned}
\text { MicCP }= & 38.7+0.23 \mathrm{FCP}+55.3 \times 10^{-3} \text { resOMtDR } \\
& +42.7 \times 10^{-3} \text { NDFduo } \\
& (n=446, n \exp =174, \mathrm{RSD}=6.5)
\end{aligned}
$$

This relationship, based on three few related criteria, reflects the respective roles of the dietary components that support microbial growth (FCP and resOMtDR) and those that allow outflow of rumen microbes from the rumen to the duodenum (NDFduo).

The positive effect of passage rate of digesta on the efficiency of microbial growth in the rumen (the 'chemostat' effect) has been clearly shown in vitro (Hespell, 1979; Demeyer and Van Nevel, 1986). To quantify this effect in vivo, data from digestion trials reporting both digesta passage rate, and microbial synthesis in the rumen, were extracted from the Bovidig database. A significant effect of $\mathrm{kpt}$ on MicCP was shown through a curvilinear overall regression fitted by a Michaelis type model.

$$
\begin{gathered}
\mathrm{MicCP}=152.5 /(1+(3.0 / \mathrm{kpt})) \\
(n=234, \mathrm{RSD}=28.7)
\end{gathered}
$$

This relationship is very close to the one reported in vitro (Demeyer and Van Nevel, 1986), and suggests a theoretical maximal production of MicCP of $152.5 \mathrm{~g} / \mathrm{kg}$ DMI. When data are corrected from the experiment effect, the RSD decreases substantially $(\mathrm{RSD}=1.1)$.

The proposal for the new INRA FUS. Several prediction equations, all based on FOM as the main driving force of microbial growth, but integrating the various other factors described above have been developed using withinexperiment regressions on data from the Bovidig database. Three of these equations were considered to be satisfactory to predict MicCP, based on the fact that they included independent predictors, and that they presented a low RSD $<7$. These equations are: equation (38), based on the positive effects of fermented $C P$, residual FOM and duodenal NDF; the following equation (40) based on the positive effects of FOM, fermented CP and particulate passage rate; the following equation (41) based on the positive effects of FOM and proportion of concentrate, and on the negative relationship with the rumen protein balance, as discussed previously.

$$
\begin{aligned}
\text { MicCP }=- & 0.85+63.1 \times 10^{-3} \mathrm{OMtDR}+0.22 \mathrm{FCP} \\
& +11.44 \mathrm{kpt}-0.88 \mathrm{kpt}^{2} \\
& (n=203, n \exp =83, \mathrm{RSD}=6.8)
\end{aligned}
$$

$$
\begin{gathered}
\mathrm{MicCP}=40.7-0.114 \mathrm{RPB}+75.6 \times 10^{-3} \mathrm{OMtDR}+8.07 \mathrm{PCO} \\
(n=637, n \exp =245, \mathrm{RSD}=6.7)
\end{gathered}
$$

These three within-experiment equations ((38), (40), (41)) presented a similar RSD (on average 6.7), lower than that of equation (37) based on FOM alone (7.6). These four equations were then compared in their ability to predict MicCP, using a global regression approach (observed MicCP $=a+b$ predicted MicCP) with all data of the Bovidig database. Only equation (41) led to a regression slope nonsignificantly different from one $(Y=X)$, with the intercept $a=4$ (not different from 0 ) and the slope $b=0.95$. The predicted changes in MicCP related to the plausible range of variation in the three explanatory variables are: 40,15 and $5 \mathrm{~g} \mathrm{MicCP} / \mathrm{kg}$ DM for OMtDR, RPB and PCO, respectively, confirming the major role of OMtDR in promoting microbial growth.

In the Systali project, the equation of prediction of microbial CP is thus based on equation (41'):

$\mathrm{MicCP}=40.7-0.114 \mathrm{RPB}+75.6 \times 10^{-3} \mathrm{FOM}+8.07 \mathrm{PCO}$

with RPB and FOM calculated as indicated in equation (12") and $\left(26^{\prime}\right)$, respectively. A negative relationship between MicCP and RPB had already been identified in the protein chapter of NRC (2001). For the feed values in the tables, MicCP is considered to depend only on FOM, with RPB and PCO fixed to 0 . With urea supplemented diets, the increase in MicCP appears to occur only through the increase in FOM (via $\triangle \mathrm{OMd}$ RPB), with no additional, specific, negative effect of urea-induced RPB (Chapoutot et al., 2013b). The external evaluation of equation (41) from OviDig (43 exp, $123 \mathrm{trt}$ ) shows an unbiased prediction of actually measured MicCP (Nozière et al., 2013).

\section{Digestion in the intestines}

Proteins in the small intestine. The principles of calculation of the PDI have been maintained, with a true digestibility (dr) fixed to $80 \%$ for microbial proteins and variable among feedstuffs for RUP. With this value, the mean dietary MP from microbial origin (PDIME, g/kg DM) for more than 1000 diets calculated for dairy cows remains the same (47.0 in the present study v. 48.2 for the previous version). However, the slope between the two data sets is different from 1, as a consequence of the slope presented in Figure 6 . The $d r$ of feed by-pass protein (RUP) is based on the results of measurements obtained with mobile nylon bags in the intestines. However, when no in situ data is available, dr can be predicted, from the flow of non-digestible dietary $\mathrm{CP}$ in the small intestine (NDCPSI):

$$
\mathrm{dr}=(\text { RUP }- \text { NDCPSI }) / \text { RUP } \times 100
$$

This principle of calculation was developed in the previous versions of the PDI system (INRA, 1978; Vérité et al., 1987), were NDCPSI was estimated from DOM and non-digestible $\mathrm{OM}$, although these criteria were correlated. The prediction of NDCPSI has been updated with the Bovidig database, using a much larger set of measurements of duodenal flows, to better describe the intestinal digestive phenomena. Several predictors of non-digestible protein (NDCP) were tested using a multiple regression approach. A combination of RUP and MicCP appeared satisfactory to predict NDCP $(52.6 \pm 12.6, \min =5.2, \max =107.4 \mathrm{~g} / \mathrm{kg} \mathrm{DM})$, that is to 
account for the respective contribution of dietary and microbial fractions to fecal CP.

$$
\begin{aligned}
& \mathrm{NDCP}=2.95+0.196 \mathrm{RUP}+0.109 \mathrm{MicCP} \\
& \quad(n=588, \mathrm{RSD}=0.90)
\end{aligned}
$$

The coefficients remained stable and the prediction was improved by adding non digestible NDF (NDNDF $=174.3 \pm$ 56.2 , $\min =56.2, \max =468.9 \mathrm{~g} / \mathrm{kg} D M)$, to account for the contribution of the endogenous fraction.

$$
\begin{aligned}
\mathrm{NDCP}= & 2.69+0.193 \mathrm{RUP}+0.106 \mathrm{MicCP} \\
& +0.022 \mathrm{NDNDF} \quad(n=484, \mathrm{RSD}=0.83)
\end{aligned}
$$

In the Systali project, the prediction of NDCPSI is based on equation (45), directly derived from equation (44):

$$
\begin{aligned}
\mathrm{NDCPSI}= & \mathrm{NDCP}-2.69-0.106 \mathrm{MicCP} \\
& -0.022 \mathrm{NDNDF}
\end{aligned}
$$

Other FU systems have suggested predicting the NDCP of the feed from the content of ADIN, or the nitrogen fraction entrapped in ADF (CNCPS, FiM). Even if in some specific situations ADIN presents interest within a specific category of feed which could be over-heated (dried grains, etc.), there appeared to be no satisfactory relationship across feeds between NDCP and feed ADIN.

Starch and fatty acids in the small intestine. The fraction of these components digested in the small intestine mainly depends on their respective duodenal flows. Data from digestion trials reporting duodenal and ileal flows of starch, or FA, were extracted from the Bovidig database. For starch digested in the small intestine (StDsi $=54.7 \pm 47.2$, $\min =0.0, \max =236.4 \mathrm{~g} / \mathrm{kg} \mathrm{DM}$ ), these confirmed the within-experiment regressions calculated by Offner and Sauvant (2004a) for starch (equation (46)).

$$
\begin{aligned}
\text { StDsi } & =74.05-0.122 \text { RUSt } \\
\quad(n & =51, n \exp =18, \text { RSD }=10.8)
\end{aligned}
$$

This equation permits calculation of the glucose that is available in the lumen of small intestine. The RUSt was defined above in equation $\left(10^{\prime}\right)$. This equation (46) has been evaluated using external data of glucose portal appearance measurements (Loncke et al., 2009). For fatty acids digestible in small intestine (FADsi $=33.7 \pm 11.7, \min =13.9, \max =61.3 \mathrm{~g} / \mathrm{kg} \mathrm{DM}$ ) it is suggested to follow the proposal of Schmidely et al. (2008) issued from a meta-analysis of the literature (equation (47)):

$$
\begin{aligned}
\text { FADsi } & =0.83 \text { FAduo }-0.0011 \text { FAduo }^{2} \\
(n & =61, n \exp =16, \mathrm{RSD}=2.80)
\end{aligned}
$$

In this equation, FAduo is calculated as defined in equation (33). By a similar meta-analytic approach, predictions of the profile of the duodenal and absorbed flows of the major LCFA, including isomers of $\mathrm{C} 18$, have been proposed (Glasser et al., 2008; Schmidely et al., 2008).

Digestion in the large intestine. There is usually a loss of $\mathrm{N}$ between the ileum and feces, which averages $10 \mathrm{~g} \mathrm{CP} / \mathrm{kg}$ DM in the Bovidig database. It primarily depends on the amount of $\mathrm{CP}$ entering the large intestine, and represents on average $50 \%$ of the ileal flow. This apparent absorption of $\mathrm{N}$ is not accounted for the calculation of PDI since it occurs mainly as ammonia $\mathrm{N}$, which will join, after processing by the liver, the body urea pool to be ejected in the urine or recycled.

The fraction of $\mathrm{OM}$ apparently disappearing in the large intestine is quite low (on average of the 112 measurements in BoviDig, $65.1 \pm 33.6 \mathrm{~g} / \mathrm{kg} \mathrm{DMl}$ ) and represents $\sim 10 \%$ of the DOM throughout the digestive tract. This fraction should be taken into account for further prediction of the VFA and gas produced in the distal part of the digestive tract.

\section{Methane and urinary energy losses}

The prediction of gross energy (GE) of feedstuffs from their chemical characteristics, and prediction of energy digestibility (Ed) from OMd (forages), or from OMd and chemical composition (concentrates and by products), have not been revised. Thus the previous equations (Baumont et al., 2007) remain unchanged. The calculation of Ed is applied to OMdc as before, assuming that digestive interactions on $\mathrm{OMd}$ similarly affect Ed. In contrast, the quantification of energy losses from $\mathrm{DE}$ to $\mathrm{ME}$ ( $\mathrm{ME}=\mathrm{DE}-\mathrm{ECH} 4-$ UrineE) has been largely updated, based on results from calorimetric chambers.

Energy losses in methane. Losses of energy through enteric $\mathrm{CH} 4$ are largely determined by the amount of digested $\mathrm{OM}$, and both $\mathrm{CH} 4$ and DOM have been widely and precisely measured using calorimetric chambers. Moreover, $\mathrm{CH} 4$ emission is also affected by digestive interactions due to $\mathrm{FL}$ and PCO (Sauvant and Giger-Reverdin, 2009). Consequently, the ratio $\mathrm{CH} 4 / \mathrm{DOM}(34.0 \pm 9.1, \min =10.9, \max =72.6 \mathrm{~g}$ $\mathrm{CH} 4 / \mathrm{kg}$ DOM) was used as the relevant basis for expressing losses in $\mathrm{CH} 4$. The effects of $\mathrm{FL}$ and PCO on $\mathrm{CH} 4 / \mathrm{DOM}$ have been quantified from results of calorimetric measurements gathered in the Rumener database. The following withinexperiment regression, already reported by Sauvant et al. (2011) was calculated:

$$
\begin{aligned}
\mathrm{CH} 4 / \mathrm{DOM}= & 45.42-6.66 \mathrm{FL}+0.75 \mathrm{FL}^{2}+19.65 \mathrm{PCO} \\
& -35.0 \mathrm{PCO}^{2}-2.69 \mathrm{FL} \times \mathrm{PCO} \\
& (n=450, n \exp =158, \mathrm{RSD}=2.3)
\end{aligned}
$$

This equation shows that methane emission (per unit DOM) is lower for high concentrate diets ingested at a high level. The interaction between FL and PCO is illustrated in Figure 7a. These results show that diets having high levels of DMI and $\mathrm{PCO}$, which have more digestive interactions at the level of OMd (or Ed), induce less loss of energy as $\mathrm{CH} 4$. This constitutes a relative compensation.

Energy losses in urine. Losses of energy in urines are largely determined by the urinary $\mathrm{N}$ and thus depend on dietary $\mathrm{N}$ level, which is most precisely expressed by rumen protein balance, as discussed previously. However, given that RPB is never measured in calorimetric chambers, CP was chosen as a relevant base against which to predict losses of energy 

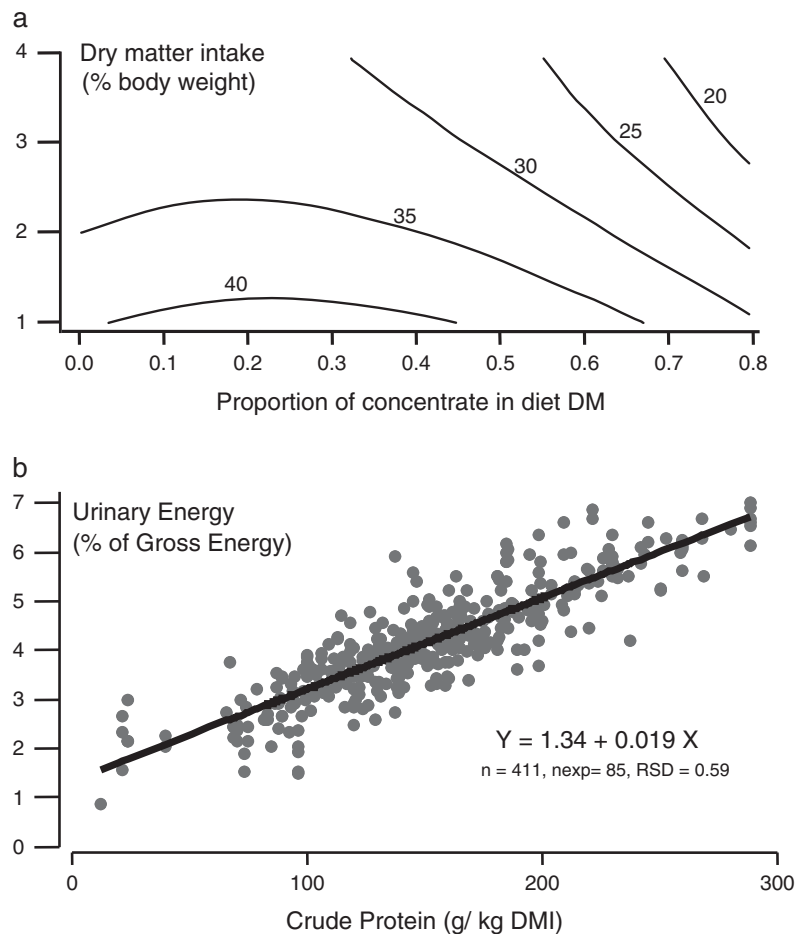

Figure $7 \mathrm{CH} 4$ and urinary energy losses: (a) curves of iso-production response of $\mathrm{CH} 4(\mathrm{~g} / \mathrm{kg} \mathrm{DOM})$ in function of the combined influences of feeding level and proportion of concentrate in the diet; (b) intraexperiment relationship between dietary $\mathrm{CP}$ and urinary energy expressed in percentage of the gross energy.

through urine. Data from experiments using $\mathrm{CP}$ content as an experimental factor were extracted from the Rumener database. The within-experiment regression between dietary CP content and urinary energy expressed in $\%$ of gross energy (UE $=4.0 \pm 1.4, \min =0.7, \max =10.3 \% \mathrm{GE}$ ) was calculated, and significant effects of FL and PCO on residuals were found, leading to the following within-experiment equation, illustrated by the Figure $7 \mathrm{~b}$ for mean values of $\mathrm{FL}$ and PCO:

$$
\begin{gathered}
\mathrm{UE} \% \mathrm{GE}=2.9+0.017 \mathrm{CP}-0.47 \mathrm{FL}-1.64 \mathrm{PCO} \\
(n=337, n \exp =109, \mathrm{RSD}=0.56)
\end{gathered}
$$

Thus, as for $\mathrm{CH} 4$, there is a relative compensation at urinary level due to the digestive interactions impacting OMd values. Compared with the previous approach based on the prediction of the ratio ME/DE from dietary $\mathrm{CP}$, crude fibre and the level of production (Vermorel et al., 1987) the present one results in a lesser loss of energy as $\mathrm{CH} 4$ and urine with increasing intake $[\mathrm{ECH} 4+\mathrm{EU}=2.00 \pm 0.50 \mathrm{MJ} / \mathrm{kg} \mathrm{DM}$, $n=1178$, Rumener database] for $\mathrm{DE}$ values greater than approximately $1.67 \mathrm{MJ} / \mathrm{kg} \mathrm{DM}$. Interestingly, this compensatory effect has previously been used in the derivation of Effective Energy units, for which the energy value was estimated to be independent of FL (Emmans, 1994).

Ultimately, on a set of more than 1000 treatments on dairy cows, the dietary ME content decreases by $0.61 \pm 0.27 \mathrm{MJ} / \mathrm{kg}$ DM for the ME calculated with the presented equations in comparison with the previous INRA system (mean decrease of $5.8 \%$ ). This difference is mainly the outcome of the digestive interactions that were not taken into consideration so far in the calculation of dietary ME.

\section{Conclusion}

In the present paper, the main digestive equations used to revise the calculation of digestible protein and metabolizable energy supply in INRA FUS have been presented, their mutual connections are summarized in Figure 8 and in the Supplementary Material S2. All known quantitative aspects of digestion of energy and protein have been revised using well traced methods of meta-analysis. The most relevant equations, which rely on hundreds of treatments (substantially more than used in previous derivations of the current national feeding systems), have been selected based on their statistical, physiological and systemic importance.

An original aspect of this approach is that the consistency across all the equations was assessed on a simple (12 compartments) mechanistic model of the rumen (Sauvant and Nozière, 2012). More detailed mechanistic models of the rumen have been published for several decades after the pioneering work of Baldwin et al. (1977). They have been all based on a bottom up process using rather few data values measured at a fairly underlying level of the rumen system, sometimes in vivo but also frequently in vitro. These models were almost not evaluated through global data and they present the common drawback of being of low accuracy (Offner and Sauvant, 2004b). The current rumen model was built through a top-down approach where underlying parameters were fitted in consistency with all the above presented equations. Finally, all the equations were implemented within a software 'systool.fr' allowing calculation of renewed dietary values and subsequently absorbed nutrient flows (Chapoutot et al., 2013a).

It is now possible to predict with a reasonable and quantifiable accuracy the changes in rates of transit of particles and liquids. These new data were utilized to better adapt the prediction equations of the rumen degradability of dietary protein and starch. This will allow valorizing the large amount of in situ data degradation published in the literature.

The question of digestive interactions has been completely revised, leading to a set of specific equations to reflect influences of the three main factors of interaction: the level of intake, the proportion of concentrate and the rumen protein balance. The FOM has also been extensively updated, to better reflect the true OMtDR, which is an essential step to more accurately predict the production of microbial protein, VFA and gas in the rumen.

It has been shown that microbial protein production is not directly proportional to the FOM, as was previously assumed, and that other factors may explain these variations. Different equations of comparable precision have been obtained. The one based on FOM, RPB and PCO appeared the more predictive and the more convenient in practice, and has thus been retained.

All these relationships were essentially built on data obtained in cattle, an external evaluation being performed on data obtained on small ruminants. 


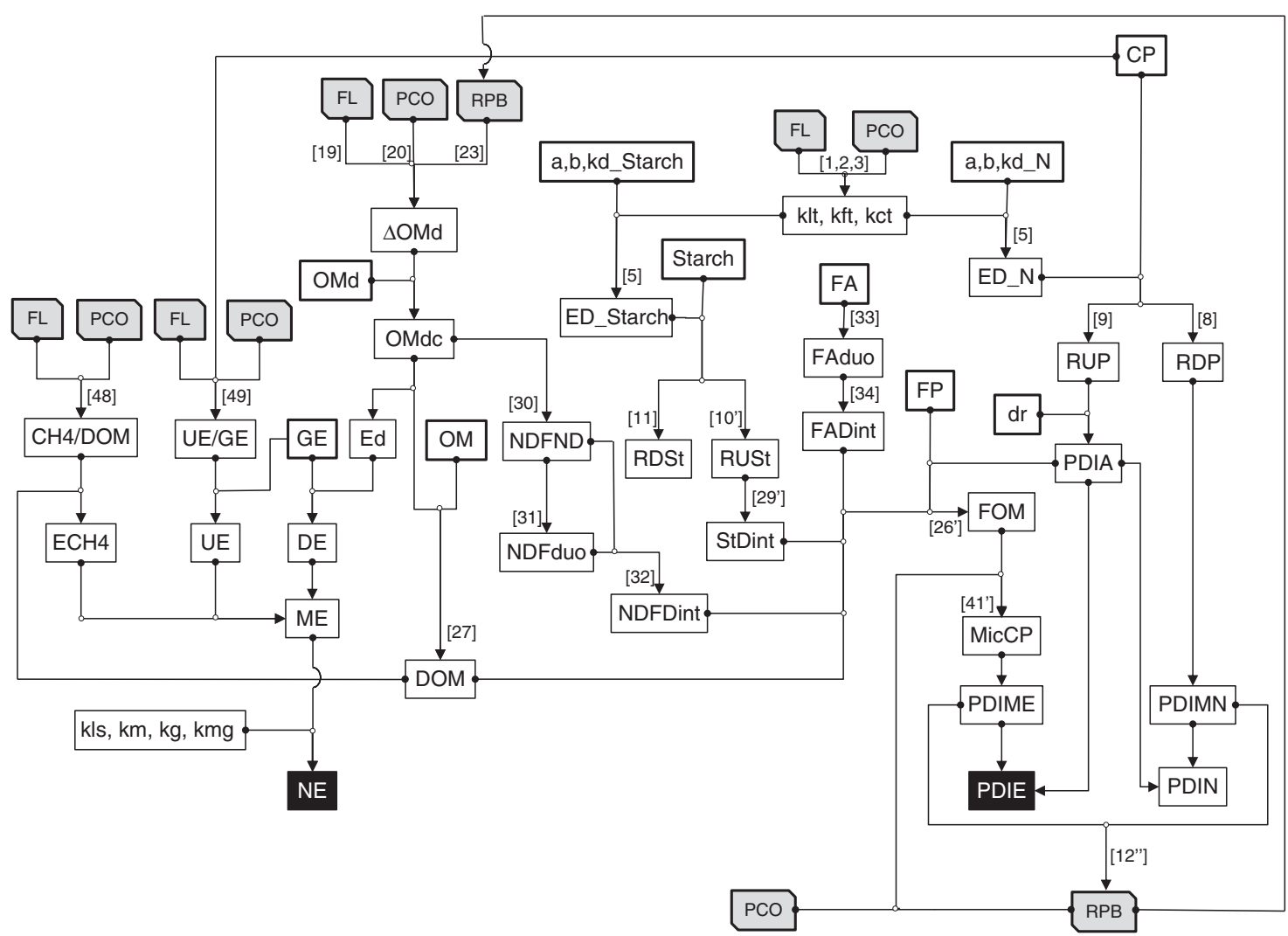

Figure 8 Calculation of the energy and protein values of feeds and diets. The entry of the model are (i) feedstuff characteristics (white boxes, bold characters), that is chemical composition (OM, CP, starch, FA, FP, GE), tabulated OM digestibility (OMd), in situ degradation parameters (a, b, kd) for starch and $\mathrm{N}$, and true digestibility of by-pass protein (dr); (ii) diet characteristics that induce digestive interactions (grey truncated boxes, bold characters), that is feeding level $(\mathrm{FL})$, proportion of concentrate (PCO) and rumen protein balance (RPB). Intermediary parameters are in white boxes and thin characters. Operational parameters for rationing (black boxes, white bold characters) are net energy (NE) and metabolisable protein (PDIE). Numbers rely to the equations presented in the text and the Supplementary material S2. Calculation of NE from ME is not presented in the text.

\section{Acknowledgements}

The authors wish to thank the INRA colleagues from UMR Herbivores (Theix), UMRMosar (Paris), UMR Pegase (Rennes), UMR Selmet (Montpellier), and URZootechnie (Guadeloupe) for valuable discussions on the different aspects covered in this text. Special thanks to Nicolas Friggens for improving the English language and the readability of the manuscript.

\section{Supplementary material}

To view supplementary material for this article, please visit http://dx.doi.org/10.1017/S1751731115002670

\section{References}

Agabriel J, Pomiès $D$, Nozières $M O$ and Faverdin $P$ 2007. Principes de rationnement des ruminants. In Alimentation des bovins, ovins et caprins. Besoins des animaux - Valeur des aliments - Tables INRA 2007, mise à jour 2010. pp. 9-22. Editions Quae, Versailles, France.

Andrieu J, Demarquilly C and Sauvant D 1988. Tables de la valeur nutritive des aliments. In Alimentation des bovins, ovins et caprins (ed. R Jarrige), pp. 351-464. INRA, Paris, France.

Archimède $H$, Sauvant $D$ and Schmidely $P$ 1997. Quantitative review of ruminal and total tract digestion of mixed diet organic matter and carbohydrates. Reproduction Nutrition Development 37, 173-189.

Assoumaya C, Sauvant D and Archimede H 2007. Etude comparative de l'ingestion et de la digestion des fourrages tropicaux et tempérés. INRA Productions Animales 20, 383-392.
Baldwin RL, Koong $\sqcup$ and Ulyatt MJ 1977. A dynamic model of ruminant digestion for evaluation of factors affecting nutritive value. Agricultural Systems 2, 255-288.

Bauchart D, Legay-Carmier F, Doreau M and Gaillard B 1990. Lipid-metabolism of liquid-associated and solid-adherent bacteria in rumen contents of dairy-cows offered lipid-supplemented diets. British Journal of Nutrition 63, 563-578.

Baumont R, Dulphy J, Sauvant D, Meschy F, Aufrère J and Peyraud J 2007. Valeur alimentaire des fourrages et des matières premières: tables et prévision. In Alimentation des bovins, ovins et caprins - Besoins des animaux - Valeurs des Aliments - Tables INRA 2007. pp. 149-179. Editions Quae, Versailles, France.

Chapoutot P, Nozière P and Sauvant D 2013a. 'Systool', a new calculator for the new French 'Systali' project. In Book of abstracts No. 19 of the 64th Annual Meeting of the European Association Federation of Animal Science, Nantes. p. 138. Wageningen Academic Publishers, the Netherlands.

Chapoutot $P$, Nozière $P$ and Sauvant D 2013b. Traduction des effets digestifs de I'urée dans les systèmes PDI et UF rénovés. Rencontres Recherches Ruminants 20, 67 .

Charlet-Lery G 1969. Methods for determination of digestibility coefficients of feeds for ruminants. European Association for Animal Production (EAAP), Report $\mathrm{n}^{\circ} 1$ from the Study Commission on Animal Nutrition, 33pp.

Demarquilly C and Weiss P 1970. Tableaux de la valeur alimentaire des fourrages. INRA Editions, Versailles, France. 64pp.

Demeyer D and Van Nevel C 1986. Influence of substrate and microbial interaction on efficiency of rumen microbial-growth. Reproduction Nutrition Development 26, 161-179.

Emmans G. C. 1994. Effective energy: a concept of energy utilization applied across species. British Journal of Nutrition 71, 801-821.

Faverdin P, Delagarde R, Delaby $L$ and Meschy F 2007. Alimentation des vaches laitières. In. Alimentation des bovins, ovins et caprins - Besoins des animaux -Valeurs des Aliments - Tables INRA 2007. pp. 23-55. Editions Quae, Versailles, France. 
Glasser F, Schmidely R, Sauvant D and Doreau M 2008. Digestion of fatty acids in ruminants: a meta-analysis of flows and variation factors: 2 . C18 fatty acids. Animal 2, 691-704.

Glasser F, Doreau M, Maxin G and Baumont R 2013. Fat and fatty acid content and composition of forages: a meta-analysis. Animal Feed Science and Technology 185, 19-34.

Guyader J, Eugène M, Nozière P, Morgavi DP, Doreau M and Martin C 2014. Influence of rumen protozoa on methane emission in ruminants: a meta-analysis approach. Animal 8, 1816-1825.

Henneberg W and Stohmann F 1860. Beiträge zur Begründung einer rationellen Fütterung der Wiederkäuer vol. 1, CA Schwetschtke and Sohn (M. Bruhn), Braunschweig, Germany.

Hespell RB 1979. Efficiency of growth by ruminal bacteria. Federation Proceedings 38, 2707-2712.

Huhtanen P, Rinne M and Nousiainen J 2009. A meta-analysis of feed digestion in dairy cows. 2. the effects of feeding level and diet composition on digestibility. Journal of Dairy Science 92, 5031-5042.

INRA-AFZ 2002. Tables de composition et de valeur nutritive des matières premières destinées aux animaux d'élevage: porcs, volailles, bovins, ovins, caprins, lapins, chevaux, poissons (ed. D Sauvant, JM Perez, G Tran), 301pp., INRA Editions, Paris, France.

INRA 1978. Alimentation des ruminants. INRA Publications, Versailles, France. 597pp. INRA 1988. Alimentation des bovins, ovins \& caprins. R Jarrige, 476pp., INRA, Paris, France.

INRA 2007. Alimentation des bovins, ovins et caprins - Besoins des animaux Valeurs des aliments - Tables INRA 2007. Editions Quae, Versailles, France. 307pp. Kristensen ES, Moller PD and Hvelplund T 1982. Estimation of the effective protein degradability in the rumen of cows using the nylon bag technique combined with the outflow rate. Acta Agriculturae Scandinavica 32, 123-127.

Loncke C, Ortigues-Marty I, Vernet J, Lapierre H, Sauvant D and Nozière P 2009. Empirical prediction of net portal appearance of volatile fatty acids, glucose, and their secondary metabolites (beta-hydroxybutyrate, lactate) from dietary characteristics in ruminants: a meta-analysis approach. Journal of Animal Science 87, 253-268.

Maxin G, Glasser F, Doreau M and Baumont R 2013. Prévision de la teneur en matières grasses et de la composition en acides gras des fourrages. Rencontres Recherches Ruminants 20, 49-52.

Michalet-Doreau B, Vérité R and Chapoutot P 1987. Méthodologie de mesure de la dégradabilité in sacco de l'azote des aliments dans le rumen. Bulletin Technique du CRZV Theix, INRA 69, 5-7.

Nousiainen J, Rinne M and Huhtanen P 2009. A meta-analysis of feed digestion in dairy cows. 1 . The effects of forage and concentrate factors on total diet digestibility. Journal of Dairy Science 92, 5019-5030.

Nozière $P$, Glasser $F$ and Sauvant $D$ 2011. In vivo production and molar percentages of volatile fatty acids in the rumen: a quantitative review by an empirical approach. Animal 5, 403-414.

Nozière P, Besle JM, Martin C and Michalet-Doreau B 1996. Effect of barley supplement on microbial fibrolytic enzyme activities and cell wall degradation rate in the rumen. Journal of the Science of Food and Agriculture 72, 235-242.

Nozière $P$, Giger-Reverdin $S$, Chapoutot $P$ and Sauvant D 2013. Quantification des interactions digestives chez les petits ruminants, résultats préliminaires. Rencontres Recherches Ruminants 20, 41-44.

NRC 2001. Nutrient requirements of dairy cattle, 7th revised edition. National Academy Press, Washington, DC, USA. 381pp.

Offner A and Sauvant D 2004a. Prediction of in vivo starch digestion in cattle from in situ data. Animal Feed Science and Technology 111, 41-56.

Offner A and Sauvant D 2004b. Comparative evaluation of the Molly, CNCPS, and LES rumen models. Animal Feed Science and Technology 112, 107-130.

Offner A, Bach A and Sauvant D 2003. Quantitative review of in situ starch degradation in the rumen. Animal Feed Science and Technology 106, 81-93.

Ørskov ER and McDonald I 1979. The estimation of protein degradability in the rumen from incubation measurements weighted according to rate of passage. Journal of Agricultural Science Cambridge 92, 499-503.

Owens FN and Goetsch AL 1986. Digesta passage and microbial protein synthesis. In Control of digestion and metabolism in ruminants (ed. LP Milligan, WL Grovum and A Dobson), pp. 196-223. Prentice-Hall, Englewood Cliffs, NJ, USA.
Sauvant D 1992. La modélisation systémique en nutrition. Reproduction Nutrition Development 32, 217-230.

Sauvant D 1999. Le concept de lois de réponses multiples aux régimes, trait d'union entre les domaines techniques et économiques de l'élevage. Rencontres Recherches Ruminants 6, 11-17.

Sauvant D, Assoumaya C, Giger-Reverdin S and Archimède H 2006. Etude comparative du mode d'expression du niveau d'alimentation chez les ruminants. Rencontres Recherches Ruminants 13, 103.

Sauvant D, Dijkstra J and Mertens D 1995. Optimisation of ruminal digestion: a modelling approach. In Recent developments in the nutrition of herbivores, Proceedings of the IVth International Symposium on the Nutrition of Herbivores, Clermont-Ferrand, INRA Editions, France, pp. 143-165.

Sauvant D and Giger-Reverdin S 2009. Modélisation des interactions digestives et de la production de méthane chez les ruminants. INRA Productions Animales 22, 375-384.

Sauvant D, Giger-Reverdin S and Meschy F 2007. Alimentation des caprins. In Alimentation des bovins, ovins et caprins - Besoins des animaux - Valeurs des Aliments - Tables INRA 2007, mise à jour 2010. pp. 139-152. Editions Quae, Versailles, France.

Sauvant D, Giger-Reverdin S, Serment A and Broudiscou L 2011. Influences des régimes et de leur fermentation dans le rumen sur la production de méthane par les ruminants. INRA Productions Animales 24, 433-446.

Sauvant $D$ and Nozière $P$ 2012. Modèle intégratif du tube digestif intégrant les interactions digestives, les flux de nutriments d'intérêt et compatible avec les systèmes UF et PDI. Rencontres Recherches Ruminants 19, 181-184.

Sauvant $D$ and Nozière $P$ 2013. La quantification des principaux phénomènes digestifs chez les ruminants: les relations utilisées pour rénover les systèmes d'unités d'alimentation énergétique et protéique. INRA Productions Animales 26, 327-346.

Sauvant D, Perez J-M and Tran G 2002. Valeurs nutritives pour les ruminants. In Tables de composition et de valeur nutritive des matières premières destinées aux animaux d'élevage (porcs, volailles, bovins, ovins, caprins, lapins, chevaux, poissons) (ed. D Sauvant, JM Perez and G Tran), pp. 43-50. INRA Editions, Paris, France.

Sauvant D, Schmidely P, Daudin JJ and St-Pierre NR 2008. Meta-analyses of experimental data in animal nutrition. Animal 2, 1203-1214.

Schmidely R, Glasser F, Doreau M and Sauvant D 2008. Digestion of fatty acids in ruminants: a meta-analysis of flows and variation factors. 1 Total fatty acids. Animal 2, 677-690.

Seo S, Tedeschi LO, Schwab CG, Garthwaite BD and Fox DG 2006. Evaluation of the passage rate equations in the 2001 dairy NRC model. Journal of Dairy Science 89, 2327-2342.

Sniffen CJ, Oconnor JD, Vansoest PJ, Fox DG and Russell JB 1992. A net carbohydrate and protein system for evaluating cattle diets. II. Carbohydrate and protein availability. Journal of Animal Science 70, 3562-3577.

Tamminga S, Vanstraalen WM, Subnel APJ, Meijer RGM, Steg A, Wever CJG and Blok MC 1994. The Dutch protein evaluation system: the DVE/OEB-system. Livestock Production Science 40, 139-155.

Thomas C 2004. Feed into milk: a new applied feeding system for dairy cows. Nottingham University Press, Nottingham, UK.

Van Duinkerken G, Blok MC, Bannink A, Cone JW, Dijkstra J, Van Vuuren AM and Tamminga S 2011. Update of the Dutch protein evaluation system for ruminants: the DVE/OEB2010 system. Journal of Agricultural Science 149, 351-367.

Vérité R, Michalet Doreau B, Chapoutot P, Peyraud J and Poncet C 1987. Revision du système des protéines digestibles dans l'intestin (PDI). Bulletin Technique du CRZV Theix 70, 19-34.

Verité R, Rulquin H, Pisulewski P and Guinard-Flament J 2001. Acides aminés digestibles dans l'intestin. Origines des variations chez les ruminants et répercussions sur les protéines du lait. INRA Productions Animales 14, 201-210.

Vermorel M and Coulon JB 1998. Comparison of the National Research Council energy system for lactating cows with four European systems. Journal of Dairy Science 81, 846-855.

Vermorel M, Coulon J and Journet M 1987. Révision du système des unités fourragères (UF). Bulletin Technique du CRZV Theix 70, 9-18.

Volden H 2011. NorFor - The Nordic feed evaluation system. EAAP Publications No 130. Wageningen Academic Publishers, the Netherlands. 180pp.

Weiss WP 1998. Estimating the available energy content of feeds for dairy cattle. Journal of Dairy Science 81, 830-839. 